\title{
Simplified loss analysis and comparison of full-bridge, full-range-ZVS DC-DC converters
}

\author{
SHUBHENDU BHARDWAJ ${ }^{1}$, MANGESH BORAGE ${ }^{2}$ and \\ SUNIL TIWARI ${ }^{2}$ \\ ${ }^{1}$ Department of Electronics and Instrumentation, Indian School of Mines \\ University, Dhanbad 826004 \\ ${ }^{2}$ Power Supplies Division, Raja Ramanna Centre for Advanced Technology, \\ Indore 452013 \\ e-mail: shubhendu.bhardwaj@gmail.com; mbb@rrcat.gov.in; sunil@ rrcat.gov.in
}

\begin{abstract}
The loss of zero-voltage-switching (ZVS) of active switches has been a serious limitation of full-bridge (FBZVS) converters. Many techniques have been proposed in the past to extend the range of ZVS operation over the wider and also the full range of operation. However, in these techniques ZVS is achieved at the expense of additional conduction loss in active switches and losses in the auxiliary components. In this paper, the analysis for the additional losses in various full-range FBZVS DC-DC converters and their comparative evaluation is reported. Closed form expressions are derived for average value of device currents and losses. The loss curves for various topologies are plotted and compared. The analytical results are found to be consistent with the experimental efficiency tests performed on $500 \mathrm{~W}, 100 \mathrm{kHz}$ prototype. It is concluded that a recently proposed new topology has the least penalty of additional losses.
\end{abstract}

Keywords. Auxiliary current; full-bridge DC-DC converters; loss analysis, ZVS.

\section{Introduction}

The full-bridge (FB) zero-voltage-switching (ZVS) converter (FBZVS converter) is a preferred topology for high power dc-dc converters due to fixed switching frequency, ZVS operation, high efficiency, low circulating reactive energy and moderate device stresses. The major limitation of the FBZVS converter has been the limited range of operation over which ZVS can be achieved. When the load current is low, the ZVS of the lagging-leg switches is lost as the energy stored in the leakage inductance of the transformer is insufficient to discharge the switch and transformer capacitances. The loss of ZVS results in increased switching losses and electromagnetic interference (EMI). In the case of high-power converters using IGBT (which is a slower device than MOSFET and exhibits current tailing at turn off), an external snubber capacitor is connected to reduce the rate of rise of voltage and turn-off losses. Therefore, in high-power converters, the loss of ZVS additionally results in the discharge of snubber capacitor in IGBT. The resulting surge current gives rise to EMI problem and stresses 
on IGBT and capacitor. Further, the resonant voltage overshoots due to resonance between the snubber capacitor and wiring/lead inductance can exceed IGBT voltage rating. Therefore, it is important to maintain ZVS operation over the entire range of operation or the conversion range. To extend the range of ZVS operation, various methods have been proposed in the past. ZVS range can be increased by utilizing the energy stored in leakage inductance, magnetizing inductance or using a saturable core inductor (Watson \& Lee 1994, Jang Yungtak et al 2003, Hua Guichao et al 1993). However, these methods do not provide complete range of ZVS operation as energy required for the ZVS still depends on either load current (when utilizing the energy of leakage inductance or employing saturable inductance) or duty cycle (when using the energy of magnetizing inductance). In order to obtain complete range of ZVS, configurations have been proposed in which, an auxiliary energy source is incorporated in the FBZVS converter, by circulating additional current in the converter. However, due to additional circulating current, these methods increase the conduction losses and other losses in additional magnetic components. Therefore, it is important to estimate the penalty of additional losses. The objective of this paper is to compare additional losses in some of these topologies. Configurations providing complete range of ZVS operation have been chosen for the study. They are:

(i) Conventional FB-PSPWM converter (Sabate et al 1990) [figure 1a]

(ii) FBZVS converter with pole on lagging leg (Watson \& Lee 1994) [figure 1b]

(iii) FBZVS converter with pole on both legs (Jain et al 2002) [figure 1c]

(iv) FBZVS converter with passive auxiliary circuit with 'adaptive' auxiliary current (Borage et al 2005) [figure 1d]

(v) New FBZVS converter with 'adaptive' auxiliary current (Borage et al 2008) [figure 1e].

In order to realize the comparison, analytical expressions of additional losses in each topology have been derived and total theoretical loss has been estimated. The conventional FBZVS converter has been chosen as the reference model, as it has no additional losses. Efficiency tests have been conducted to confirm the trend. The expressions for the average device currents are derived for simplified loss analysis with IGBT switches. Loss analysis for MOSFET switches can be done on the similar lines. The only difference would be to derive the expressions for rms currents in the switches to calculate MOSFET on-state losses.

\subsection{Assumptions and methodology of the simplified loss analysis}

IGBTs are used for the high-power application of proposed FBZVS converter. To calculate the conduction losses in the IGBT switches and anti-parallel diodes as well as the losses in the auxiliary inductor over the entire conversion range, following simplifying assumptions are made:

(a) The output current is ripple-free, therefore transformer primary current is square-wave.

(b) Transformer leakage inductance is small, therefore the slew interval (during which the transformer primary current reverses its direction) is absent.

(c) The average power loss in an IGBT and a diode is proportional to the average current flowing through them.

Total additional losses in the converter include conduction losses in the devices, core and resistive losses of the additional magnetic components. Core losses and the resistive losses are significant due to increased number of magnetic components in the converter. 
In order to calculate average device currents, the currents flowing through the midpoints of the legs in any of the converter configurations (points $A$ and $B$ in figure 1a-e or bridge points), i.e. $I_{A}$ and $I_{B}$, are first calculated. These currents are either the sum or difference of the transformer primary current $\left(I_{p r i}\right)$ and auxiliary current (or the current through the auxiliary inductance; $I_{a}$ ), if any. Then the current waveforms through the individual switch/diode can be obtained depending upon the gate pulses and the positive/negative value of the current flowing

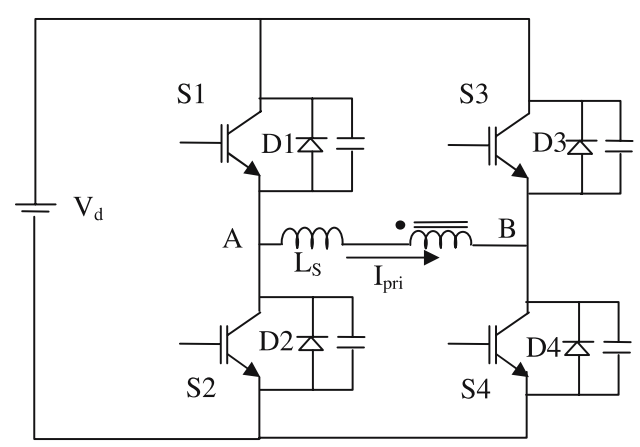

(a)

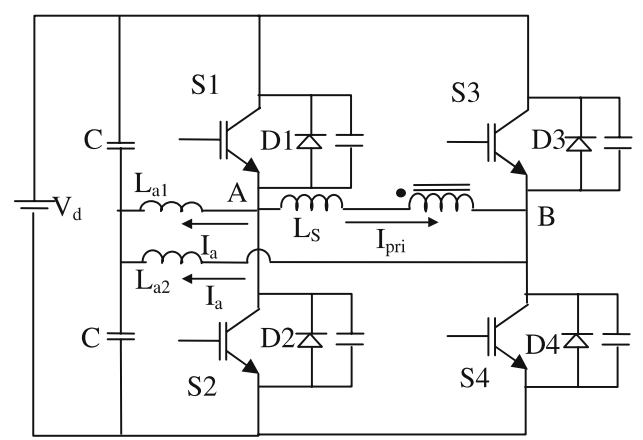

(c)

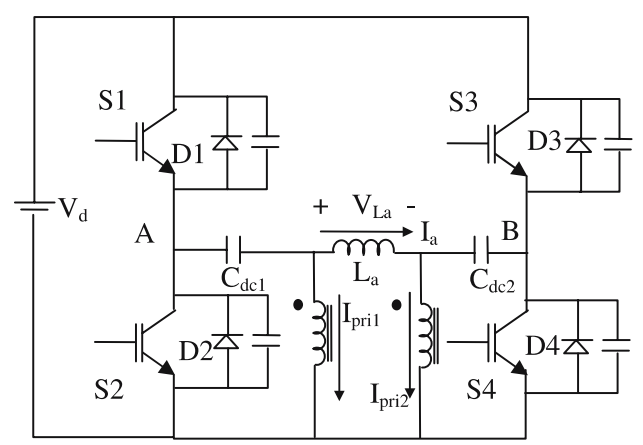

(e)

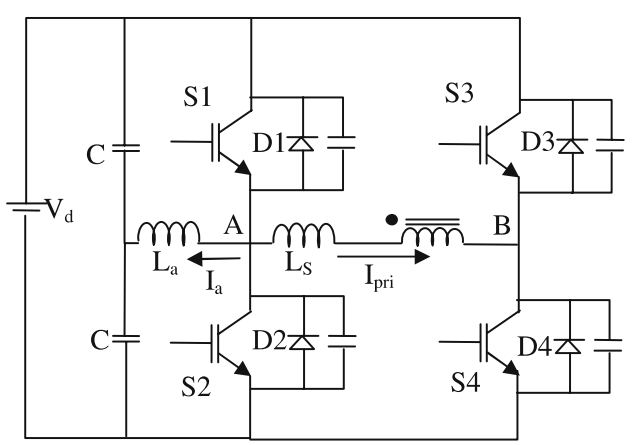

(b)

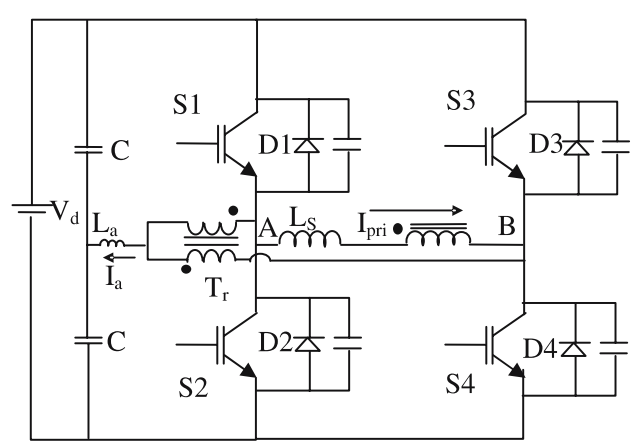

(d)

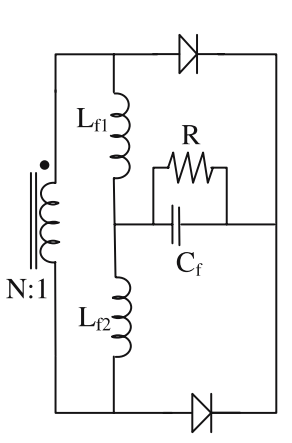

(f)

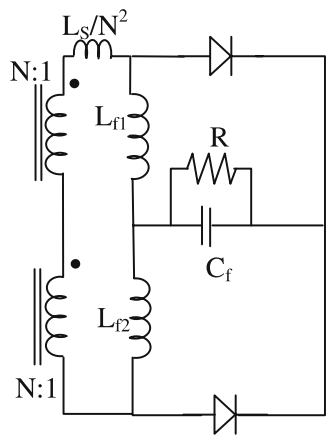

(g)

Figure 1. Various converter configurations under study (a) Conventional PSPWM converter; (b) Converter with pole at lagging leg; (c) Converter with pole at both the legs; (d) Converter with passive auxiliary circuit and 'adaptive' current; (e) New FBZVS Converter with 'adaptive' current; (f) Secondary side current doubler for converters (a)-(d); (g) secondary side current doubler for converter (e). 
through the midpoints of the legs. Average values of the individual currents are calculated and an expression for conduction loss in each switch and the body diode is obtained. Core losses and the resistive losses in the additional magnetic components are derived in the respective topologies. Total loss, which is the sum of the conduction loss in all the devices and the core and resistive losses in the magnetic components, is then plotted for each topology for comparison.

\section{Conventional FBZVS converter}

For the conventional FBZVS circuit [figure 1a, f] the device current-waveforms are shown in figure 2. In figure 2, transition from $S_{2}$ to $S_{1}$ will be soft switched for higher values of duty ratio, as the energy of the leakage inductance will be sufficient to produce ZVS in the lagging leg switches. For lower values of duty cycle this transition will be hard switched causing switching losses. $i_{s 1}-i_{s 4}$ are the switch currents in the switches $S_{1}-S_{4}$ whereas $i_{d 1}-i_{d 4}$ are diode currents in the diodes $D_{1}-D_{4}$, respectively. The dotted curve [figure 2] (in waveform $\left.I_{A}=-I_{B}\right)$ shows the primary current with ripples due to output filter inductance $\left(L_{f 1}\right.$ and $L_{f 2}$ ) [figure 1f]. The dotted waveform has been approximated to square-wave (solid curve in $I_{A}=-I_{B}$ ), for the ease of analysis, according to assumption 1 in $\S 3$. The expressions for average value of device currents can be derived as:

$$
I_{D 1+2}=0
$$

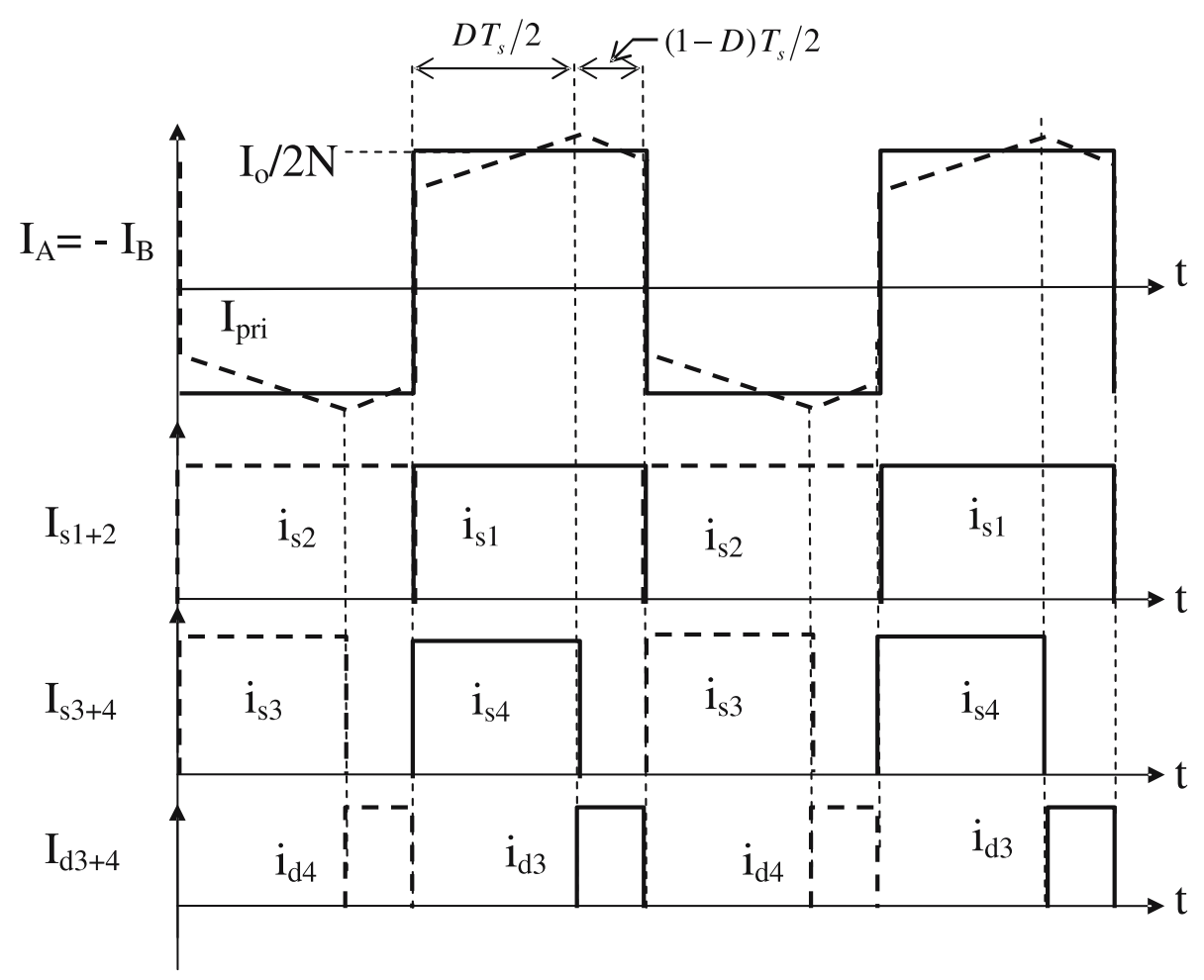

Figure 2. Device current waveforms in conventional FBZVS converter. 


$$
\begin{aligned}
I_{s 1+2} & =\frac{I_{o}}{2 N} \\
I_{D 3+4} & =\frac{I_{o}}{2 N}(1-D) \\
I_{s 3+4} & =\frac{I_{o}}{2 N} D .
\end{aligned}
$$

Here $I_{0}$, the output DC load current, can be written as $V_{d} D /(2 N R)$. The conduction loss can be given as:

$$
P_{\text {conduction }}=\frac{V_{d}}{4 N^{2} R}\left[D\left(V_{o n}+V_{d i}\right)+D^{2}\left(V_{o n}-V_{d i}\right)\right] .
$$

As mentioned in $\S 3$, transformer leakage inductance is neglected in this analysis. Therefore, the slew interval (during which the transformer primary current reverses its direction) is absent and current reverses its direction instantaneously. Since diodes $D_{1}$ and $D_{2}$ normally come into conduction during the part of this slew interval (which is assumed to be absent), $I_{D 1+2}=0$ and the waveforms of $i_{d 1}$ and $i_{d 2}$ are not shown in the figure 2 .

\section{FBZVS converter with pole at lagging leg}

In converter with pole circuit at lagging leg (figure $1 \mathrm{~b}, \mathrm{f}$ ), ZVS operation in the lagging leg for low values of primary current, $I_{p r i}$, is assisted by additional triangular inductor current $\left(I_{a}\right)$ through the pole inductance, $L_{a}$. Waveform of $I_{A}$, being sum waveform of $I_{a}$ and $I_{p r i}$, will be different for the cases $I_{p r i}>I_{L a}$ and $I_{p r i}<I_{L a}$, as shown in figures 3(a) and (b), respectively, where, $I_{L a}$ is the peak value of $I_{a}$. The boundary condition $I_{p r i}=I_{L a}$ can be expressed in the form of parameter $D_{\text {boundary }}=\left(N^{2} R / 2 F_{s} L_{a}\right)$. The expressions for the device average currents for $D>D_{\text {boundary }}$ are similar as obtained in conventional converter [equations (1a)-(1d)]; for the case $D<D_{\text {boundary }}$ the expressions for average device currents in terms of load current $I_{o}=V_{d} D /(2 N R)$ and peak auxiliary current $I_{L a}=V_{d} /\left(8 L_{a} F_{s}\right)$ are derived as:

$$
\begin{aligned}
I_{D 1+2} & =\frac{1}{2}\left(I_{L a}-\frac{I_{o}}{2 N}\right) \frac{t_{x}}{T_{s} / 2}=\left(I_{L a}-\frac{I_{o}}{2 N}\right) \frac{t_{x}}{T_{s}} \\
I_{s 1+2} & =\frac{1}{2}\left(\frac{I_{o}}{2 N}+I_{L a}\right) \frac{\left\{T_{s} / 2-t_{x}\right\}}{T_{s} / 2}=\left(\frac{I_{o}}{2 N}+I_{L a}\right)\left(\frac{1}{2}-\frac{t_{x}}{T_{s}}\right) \\
I_{D 3+4} & =\frac{I_{o}}{2 N}(1-D) \\
I_{s 3+4} & =\frac{I_{o}}{2 N} D .
\end{aligned}
$$

The time interval $t_{x}$ (figure $3 \mathrm{~b}$ for definition) is derived as,

$$
t_{x}=\left(T_{s} / 4\right)-\left(D L_{a} / 2 N^{2} R\right) .
$$

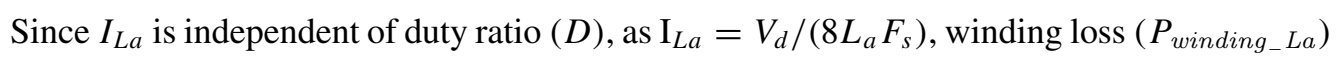
and core loss $\left(P_{\text {core }} L a\right)$ in auxiliary inductor $L_{a}$ are constant over the entire range of duty 
ratio and are decided by the design. The expressions for various losses are summarized in table 1 for both the cases. These losses are added at all duty cycle operations. This constant addition of loss may be justified at lower duty cycle operation due to attainment of ZVS, but degrades the converter efficiency at higher duty cycle operation.

\section{FBZVS converter with pole at both legs}

To obtain additional losses in this converter (figures 1c, f), similar method is adopted and average value of current in each body diode and switch is calculated. As there are two new circulating currents (one in each leg [figure 1c]) and $D_{\text {boundary }}$ will be different for the two legs, the analysis is done separately for leading and lagging the legs. The waveforms for the lagging leg current $\left(I_{A}\right)$ in this converter remains same as $I_{A}$ in converter with pole at lagging leg $\left[I_{A}\right.$ in figure 3], but leading leg waveform is the difference of $I_{a}$ and $I_{p r i}$.

Figure 4 shows the leg waveform $\left(I_{B}\right)$ in the cases when $I_{p r i}>I_{L a}$ and $I_{p r i}<I_{L a}, I_{L a}$ being the peak auxiliary current. Average values of currents in each device are calculated for both conditions of $D$ using the waveforms $I_{A}$ and $I_{B}$. Expressions for the average currents in

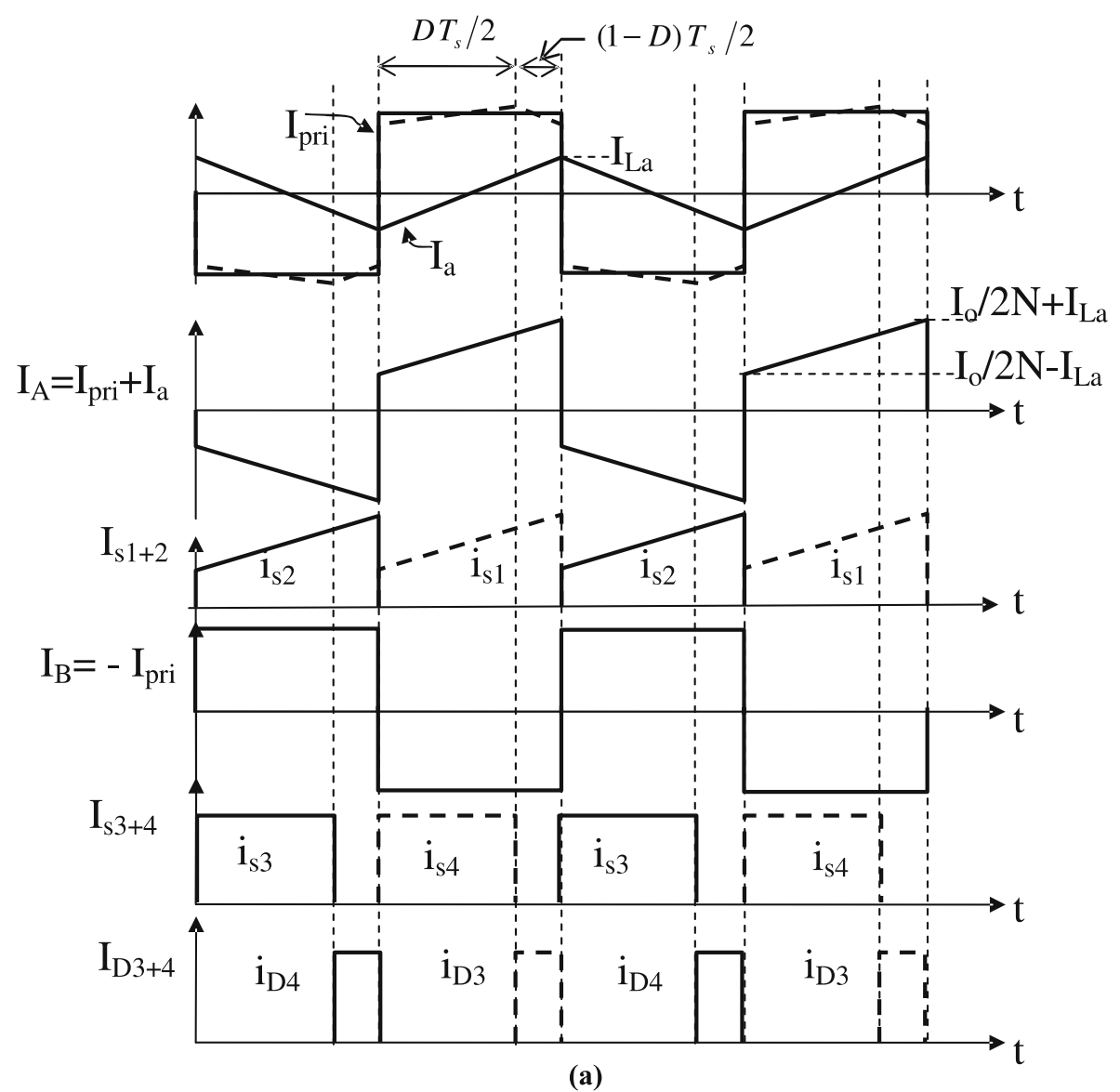

Figure 3a. (Continued) 


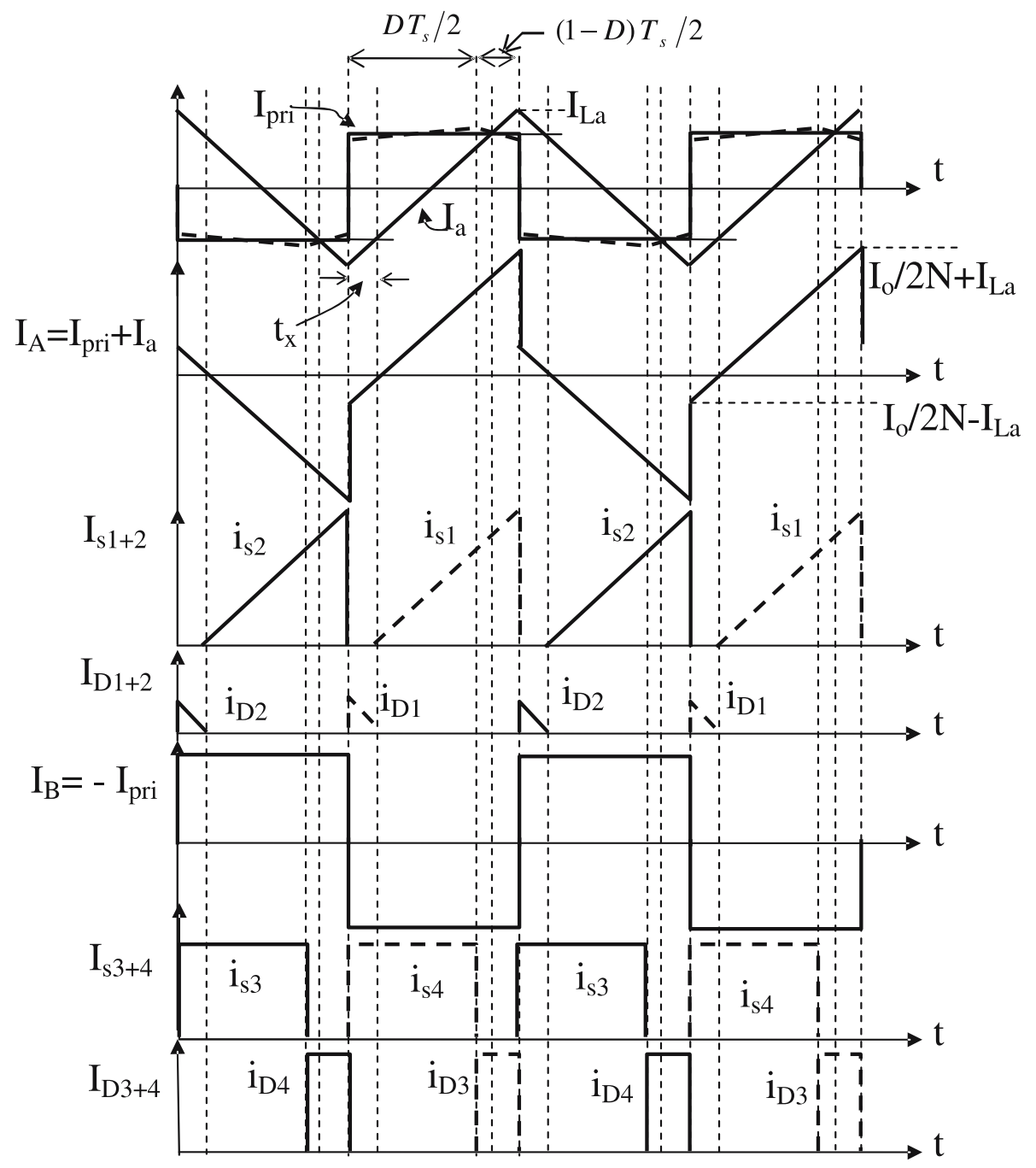

(b)

Figure 3b. Device current waveforms in FBZVS converter with pole at lagging leg for (a) $D>D_{\text {boundary }}$, and, (b) $D<D_{\text {boundary }}$.

the devices for the leading and lagging legs in terms of load current $I_{o}=V_{d} D /(2 N R)$ and peak auxiliary current $I_{L a}=V_{d} /\left(8 L_{a} F_{s}\right)$, where, $I_{L a 1}=I_{L a 2}=I_{L a}$, are given in equation set 3 .

For $D>D_{\text {boundary }}$,

$$
\begin{aligned}
& I_{D 1+2}=0 \\
& I_{s 1+2}=\frac{I_{o}}{2 N}
\end{aligned}
$$




$$
\begin{aligned}
I_{D 3+4} & =\left(I_{L a} D+\frac{I_{o}}{2 N}\right)(1-D) \\
I_{s 3+4} & =\left(I_{L a}(1-D)+\frac{I_{o}}{2 N}\right) D .
\end{aligned}
$$

And, for $D<D_{\text {boundary }}$,

$$
\begin{aligned}
I_{D 1+2} & =\left(I_{L a}-\frac{I_{o}}{2 N}\right) \frac{t_{x 1}}{T_{s}} \\
I_{s 1+2} & =\left(\frac{I_{o}}{2 N}+I_{L a}\right)\left(\frac{1}{2}-\frac{t_{x 1}}{T_{s}}\right) \\
I_{D 3+4} & =\left(I_{L a}+\frac{I_{o}}{2 N}\right)\left(\frac{1-D}{2}-\frac{t_{x 2}}{T_{s}}\right) \\
I_{s 3+4} & =\frac{I_{o}}{2 N}\left(D-\frac{t_{x 2}}{T_{s}}\right)+I_{L a}\left(D-D^{2}+(1-2 D) \frac{t_{x 2}}{T_{s}}\right) .
\end{aligned}
$$

The time interval $t_{x 1}$ corresponds to the case of lagging leg and is same as $t_{x}$ in equation 2(e) (figure $3 \mathrm{~b}$ ). The time interval $t_{x 2}$ for leading leg is defined in equation $3(\mathrm{j})$ (figure $4 \mathrm{~b}$ for definition).

$$
\begin{aligned}
& t_{x 1}=1 / 4 F_{s}-\left(D L_{a}\right) /\left(2 N^{2} R\right) \\
& t_{x 2}=1 / 4 F_{s}-\left(D L_{a}\right) /\left(2 N^{2} R\right)-D /\left(2 F_{S}\right) .
\end{aligned}
$$

\begin{tabular}{|c|c|}
\hline $\begin{array}{l}P_{\text {conduction }} \\
\quad \text { for } D \leq \frac{N^{2} R}{2 F_{s} L_{a}}\end{array}$ & $\begin{array}{l}D^{2}\left(\frac{V_{d}}{4 N^{2} R}\right)\left(V_{o n}-V_{d i}\right)+D\left(\frac{V_{d}}{4 N^{2} R}\right)\left[V_{d i}\left(1-\frac{t_{x}}{T_{s}}\right)+V_{o n}\left(\frac{1}{2}-\frac{t_{x}}{T_{s}}\right)\right] \\
\quad+\frac{V_{d}}{8 L_{a} F_{s}}\left[V_{d i} \frac{t_{x}}{T_{s}}+V_{o n}\left(\frac{1}{2}-\frac{t_{x}}{T_{s}}\right)\right]\end{array}$ \\
\hline $\begin{array}{l}P_{\text {conduction }} \\
\quad \text { for } D>\frac{N^{2} R}{2 F_{s} L_{a}}\end{array}$ & $\frac{V_{d}}{4 N^{2} R}\left[D\left(V_{o n}+V_{d i}\right)+D^{2}\left(V_{o n}-V_{d i}\right)\right]$ \\
\hline$P_{\text {core }_{-} L a}$ & Decided by the design \\
\hline$P_{\text {winding_La }}$ & $\left(\frac{V_{d}^{2}}{192 L_{a}^{2} F_{s}^{2}}\right)_{\text {coil }}^{R}$ \\
\hline
\end{tabular}

Finally, the expressions for the conduction losses in each leg are derived. These losses along with core and winding loss are listed in table 2 . It can be observed that core and winding losses are doubled, which severely degrade the converter performance as shown later in sections.

Table 1. Expressions for conduction loss, core loss and winding loss in converter with pole at lagging leg. 


\section{Converter with passive auxiliary circuit}

The device current waveforms for the converter with auxiliary passive circuit (figure $1 \mathrm{~d}, \mathrm{f}$ ) with 'adaptive' current, is shown in figure 5. As the converter incorporates an 'adaptive' auxiliary current $\left(I_{L a}\right.$ decreases with increase in $\left.I_{p r i}\right)$, the device conduction loss reduces for higher duty cycle operation as compared to previous two configurations, tending to attain loss profile of conventional FBZVS converter for $D \geq D_{\text {boundary }}$, where $D_{\text {boundary }}=$ $N^{2} R /\left(N^{2} R+2 F_{S} L_{a}\right)$. Expressions for the average currents in the devices for the leading and lagging legs in terms of load current $I_{o}=V_{d} D /(2 N R)$ and auxiliary current $I_{L a}=V_{d}(1-D) /\left(8 L_{a} F_{s}\right)$ are given in equation set (4).

For $D>D_{\text {boundary }}$ :

$$
\begin{aligned}
I_{D 1+2} & =0 \\
I_{s 1+2} & =\frac{I_{o}}{2 N}(1-D)+\left(\frac{I_{o}}{2 N}-I_{L a}\right) D=\frac{I_{o}}{2 N}-I_{L a} D \\
I_{D 3+4} & =\frac{I_{o}}{2 N}(1-D) \\
I_{s 3+4} & =\left(I_{L a}+\frac{I_{o}}{2 N}\right) D .
\end{aligned}
$$

For $D<D_{\text {boundary }}$ :

$$
I_{D 1+2}=\frac{1}{2}\left(I_{L a}-\frac{I_{o}}{2 N}\right) \frac{t_{x}}{T_{S} / 2}+\left(I_{L a}-\frac{I_{o}}{2 N}\right) D=\left(I_{L a}-\frac{I_{o}}{2 N}\right)\left(D+\frac{t_{x}}{T_{s}}\right)
$$

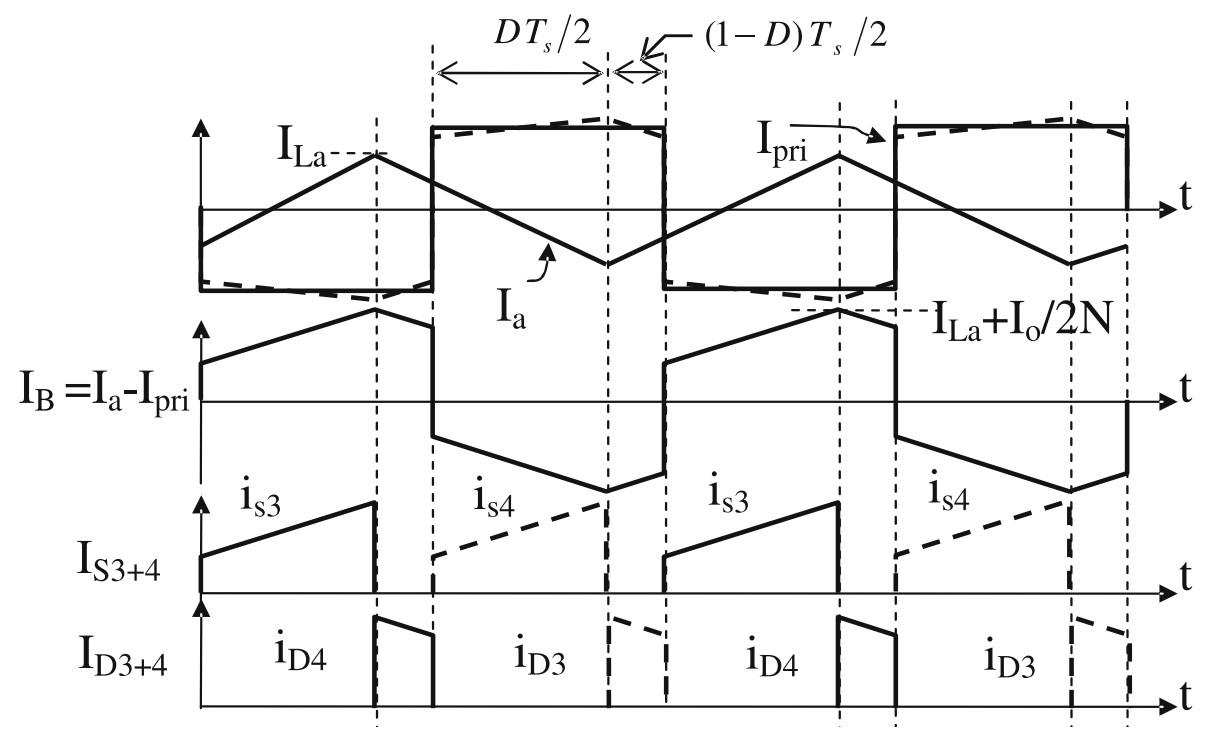

(a)

Figure 4a. (Continued) 


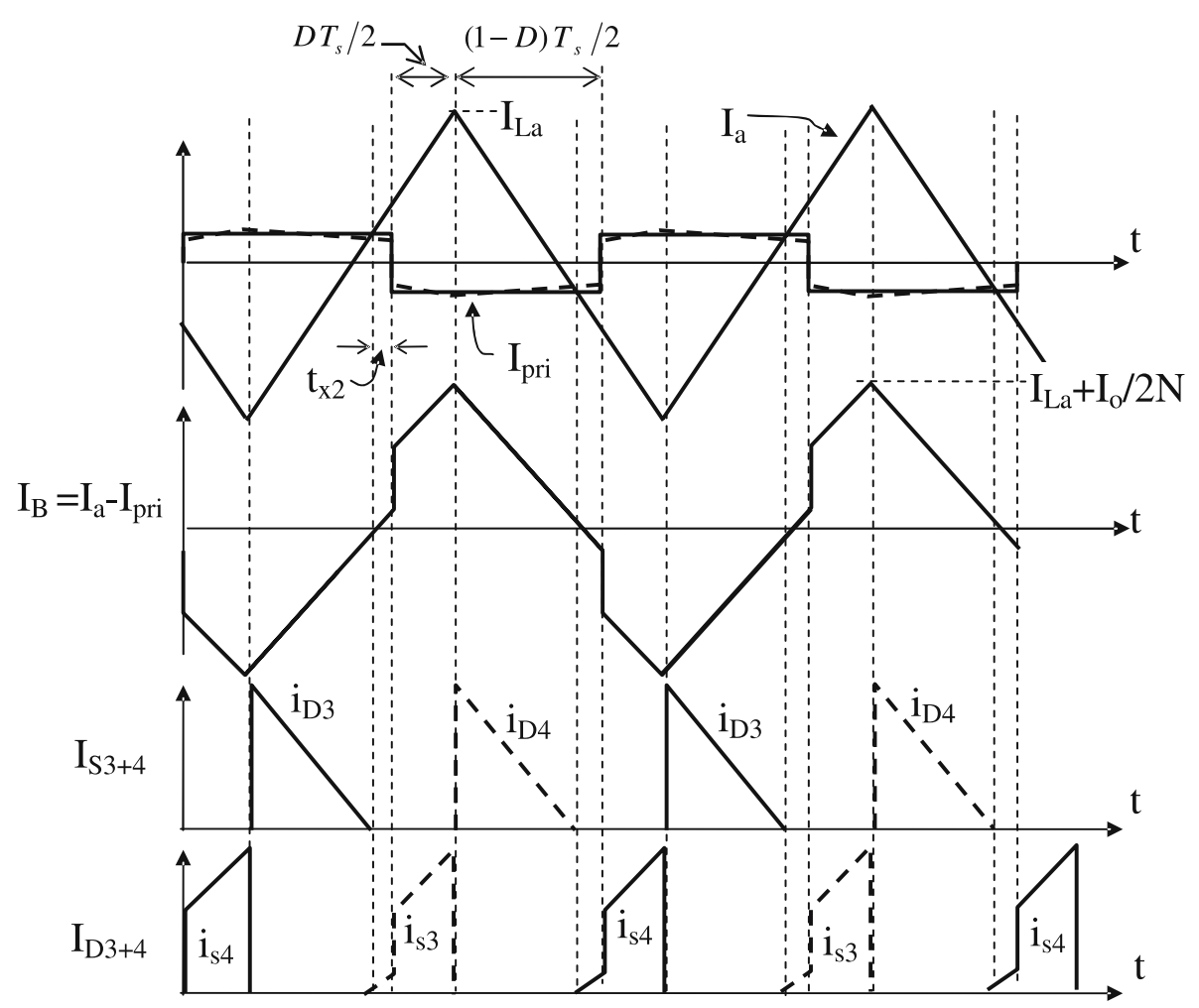

(b)

Figure 4b. Device current waveforms for the leading leg in FBZVS converter with pole at both legs for (a) $D>D_{\text {boundary }}$, and, (b) $D<D_{\text {boundary }}$.

$$
\begin{aligned}
I_{s 1+2} & =\frac{1}{2}\left(\frac{I_{o}}{2 N}+I_{L a}\right) \frac{\left\{(1-D) T_{s} / 2-t_{x}\right\}}{T_{s} / 2}=\left(\frac{I_{o}}{2 N}+I_{L a}\right)\left(\frac{1-D}{2}-\frac{t_{x}}{T_{s}}\right) \\
I_{D 3+4} & =\frac{1}{2}\left(\frac{I_{o}}{2 N}+I_{L a}\right) \frac{\left\{(1-D) T_{s} / 2-t_{x}\right\}}{T_{s} / 2}=\left(\frac{I_{o}}{2 N}+I_{L a}\right)\left(\frac{1-D}{2}-\frac{t_{x}}{T_{s}}\right) \\
I_{s 3+4} & =\frac{1}{2}\left(I_{L a}-\frac{I_{o}}{2 N}\right) \frac{t_{x}}{T_{s} / 2}+\left(I_{L a}+\frac{I_{o}}{2 N}\right) D \\
& =\left(I_{L a}-\frac{I_{o}}{2 N}\right) \frac{t_{x}}{T_{s}}+\left(I_{L a}+\frac{I_{o}}{2 N}\right) D .
\end{aligned}
$$

The time interval $t_{x}$ (see figure $5 \mathrm{~b}$ for definition) is derived as,

$$
t_{x}=\frac{1}{4 F_{s}}-D\left(\frac{1}{4 F_{s}}+\frac{L_{a}}{2 N^{2} R}\right) .
$$


Table 2. Expressions of conduction loss, core loss and winding loss in converter with pole at both legs.

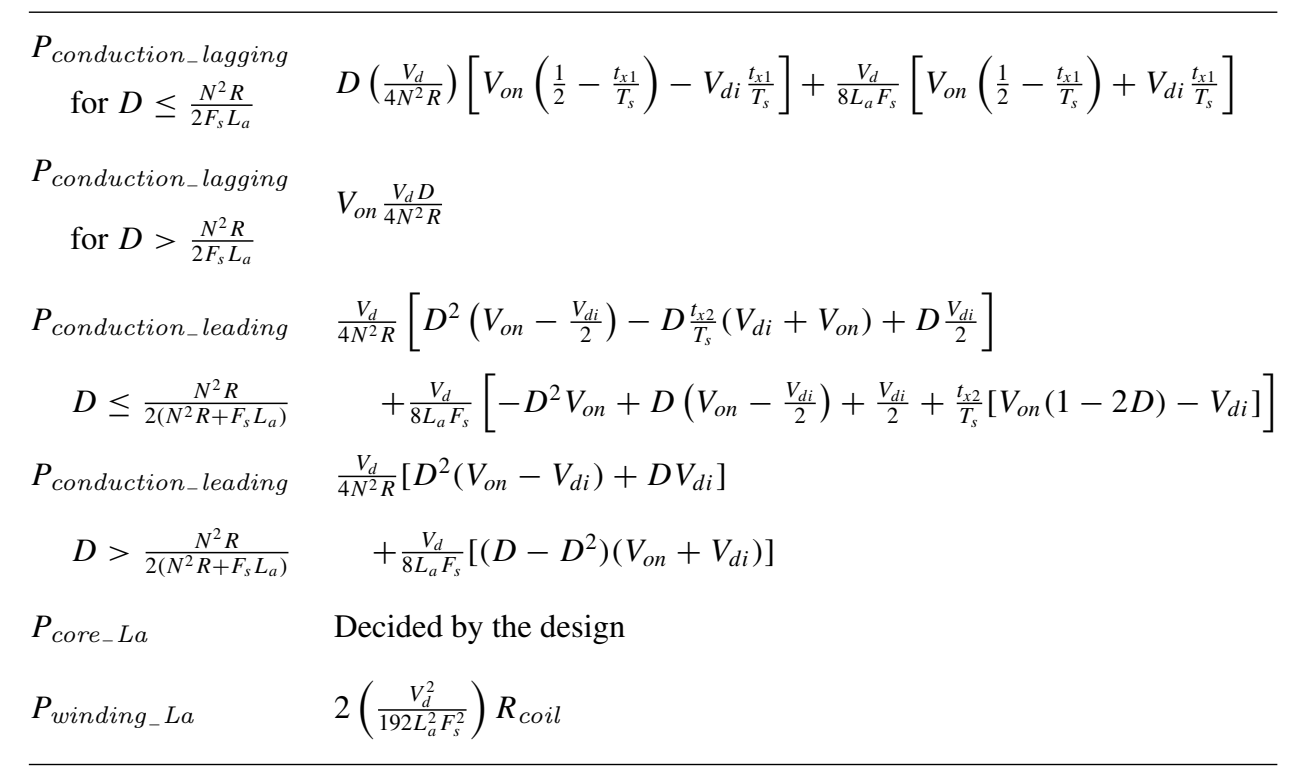

The expressions for the conduction losses in each leg are derived. These losses along with core and winding loss are listed in table 3.

The core loss of ferrites is often expressed in the form of following curve-fit equation.

$$
P_{\text {core }}=k F_{s}^{\alpha} B^{\beta},
$$

where $k, \alpha$ and $\beta$ are the constants and their values depend on the material grade. In the auxiliary inductor of the proposed converter, $F_{s}$ is constant and $B$ is proportional to $I_{L a}$, which is proportional to $(1-D)$. Therefore, core loss in the auxiliary inductor can be expressed as,

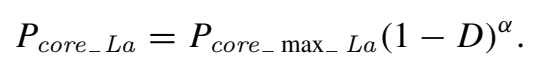

The winding loss in the auxiliary inductor are given by,

$$
\begin{aligned}
& P_{\text {winding }}=I_{L a, r m s}^{2} R_{\text {coil_La }} \\
& I_{L a, r m s}=\frac{V_{d}(1-D)}{8 \sqrt{3} L_{a} F_{s}} \sqrt{2 D+1} .
\end{aligned}
$$

Similarly, for auxiliary transformer, the core loss and winding loss are given by,

$$
\begin{aligned}
& P_{\text {core }-T r}=P_{\text {core_ } \max _{-} T r}(1-D)^{\alpha} \\
& P_{\text {winding } T r}=\frac{1}{4} I_{L a, r m s}{ }^{2} R_{\text {Core }-T r} .
\end{aligned}
$$




\section{New FBZVS converter}

Figures 1e and g show the circuit of the new FBZVS topology (Borage et al 2008). The gate pulses in the converter, generated by the control circuitry, are similar to the basic model of PS-PWM converter. Voltages $V_{d}$ and zero appear at the midpoint of the leg 1 (point A), when switch $S_{1}$ and $S_{2}$ are on, respectively. The DC blocking capacitor $C_{c d 1}$ blocks the DC components in this pulsed voltage at point $\mathrm{A}$ and $\mathrm{a} \pm V_{d} / 2$ appears at left terminal of $L_{a}$. Similarly, at the other end of $L_{a}, V_{d} / 2$ and $-V_{d} / 2$ appears when switches $S_{3}$ and $S_{4}$ are on,

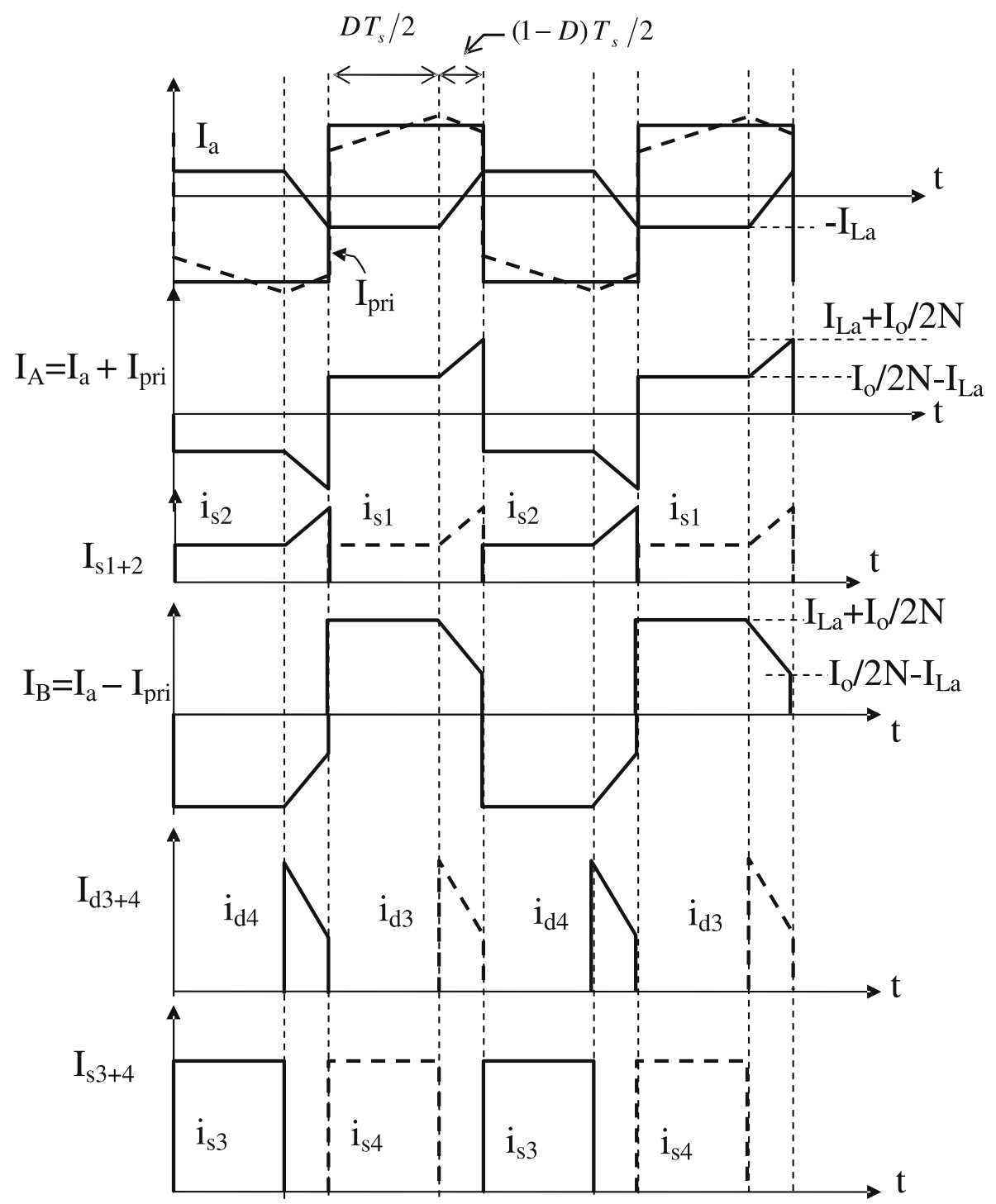

(a)

Figure 5a. (Continued) 


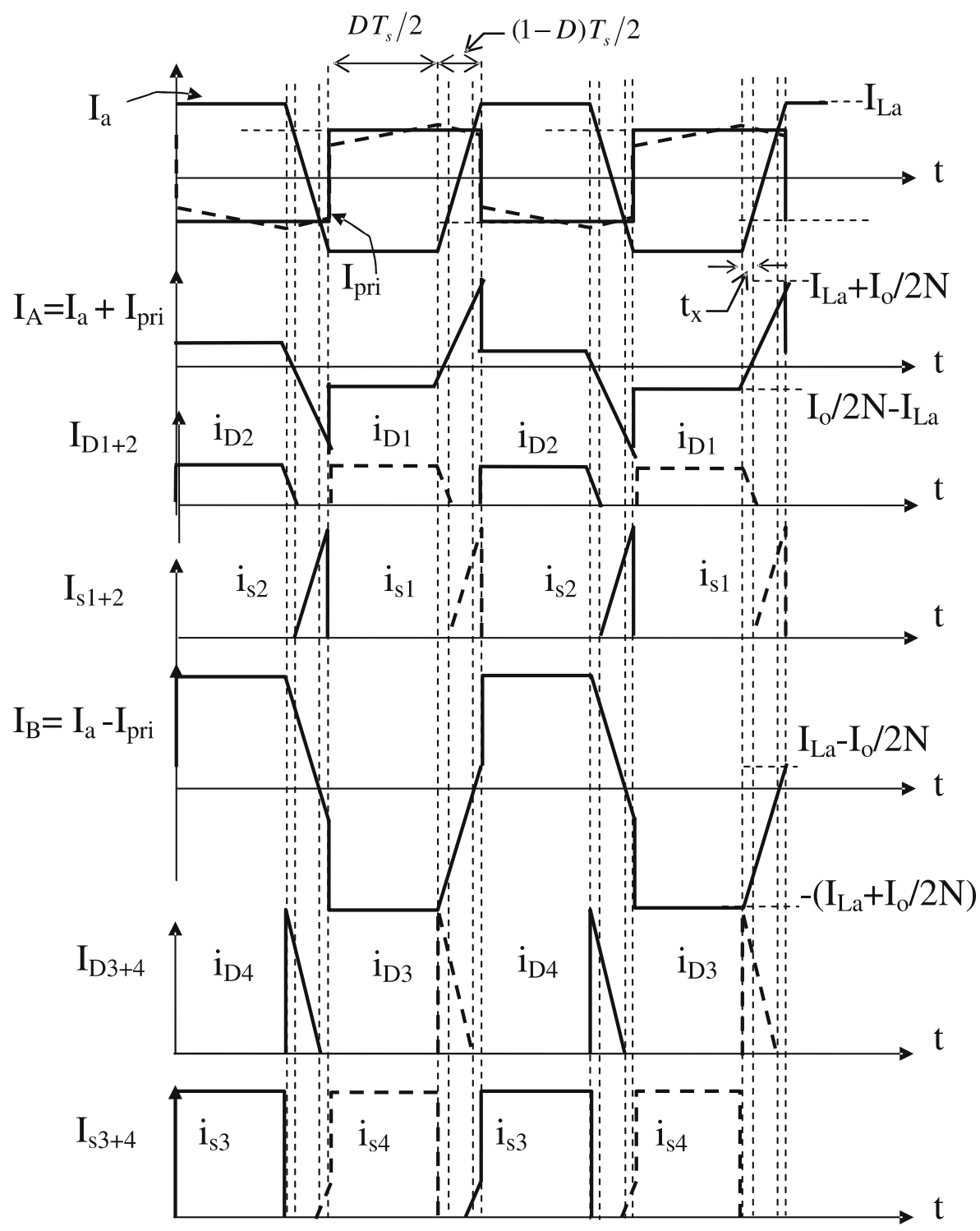

(b)

Figure 5b. Device current waveforms in converter with Auxiliary circuit and 'adaptive' current (a) $D>D_{\text {boundary }}$, and, (b) $D<D_{\text {boundary }}$.

respectively. During the time interval $D T_{s} / 2$, switches $S_{1}$ and $S_{3}$ are on providing $+V_{d} / 2$ across both transformer primaries, producing positive output pulse. Next, during $(1-D)$. $T_{s} / 2$ period, switches $S_{1}$ and $S_{4}$ are on, producing voltages $+V_{d} / 2$ and $-V_{d} / 2$ across the transformer primaries, which add up to zero at the secondary. During this period, net voltage of $V_{d}$ is obtained across $L_{a}$, producing auxiliary current which rises during $(1-D) \cdot T_{s} / 2$. Similar operation with opposite voltage polarities is obtained for next $D \cdot T_{s} / 2$ and $(1-D) \cdot T_{s} / 2$ 
Table 3. Expressions of conduction loss, core loss and winding loss in converter with auxiliary circuit with adaptive current.

\begin{tabular}{|c|c|}
\hline$P_{\text {conduction }}$ & $\frac{V_{d}}{16 F_{s} L_{a}}\left(V_{o n}-V_{d i}\right)-D^{2}\left[\frac{V_{d}}{4 N^{2} R}\left(V_{d i}-V_{o n}-\left(V_{d i}+V_{o n}\right) \frac{L_{a} F_{s}}{N^{2} R}\right)\right.$ \\
\hline for $D \leq \frac{N^{2} R}{N^{2} R+2 F_{s} L_{a}}$ & $\left.+\frac{V_{d}}{16 F_{s} L_{a}}\left(V_{o n}-V_{d i}\right)\right]$ \\
\hline $\begin{array}{l}P_{\text {conduction }} \\
\quad \text { for } D>\frac{N^{2} R}{N^{2} R+2 F_{s} L_{a}}\end{array}$ & $\frac{V_{d}}{4 N^{2} R}\left[D\left(V_{o n}+V_{d i}\right)+D^{2}\left(V_{o n}-V_{d i}\right)\right]$ \\
\hline$P_{\text {core }_{-} L a}$ & $P_{\text {core } \_\max _{-} L a}(1-D)^{\alpha}$ \\
\hline$P_{\text {core }}$ Tr & $P_{\text {core }_{-} \max _{-} \operatorname{Tr}} D^{\alpha}$ \\
\hline$P_{\text {winding_La }}$ & $\frac{V_{d}^{2}(1-D)^{2}}{192 L_{a}^{2} F_{s}^{2}}(2 D+1) R_{\text {core }} L a$ \\
\hline$P_{\text {winding }} T r$ & $\frac{V_{d}^{2}(1-D)^{2}}{768 L_{a}^{2} F_{s}^{2}}(2 D+1) R_{\text {core_ }} \operatorname{Tr}$ \\
\hline
\end{tabular}

periods. Since the auxiliary current rises in the complementary duty cycle period, $I_{L a}$ is high for lower duty ratio operation and vice-versa.

Figure 6 shows the device currents waveforms for the new FBZVS converter (figures 1e, g). Table 4 gives the summary of calculated additional losses incurred in the new converter in order to attain full range ZVS. As extra circulating current $\left(I_{a}\right)$ in the converter is 'adaptive' (i.e. it decreases with increasing $I_{p r i}$ ), additional conduction losses, core loss and winding loss all tend to reduce with increasing duty cycle. Due to this, the conduction losses in the converter tend to converge with conduction losses in the conventional converter for higher duty cycle operation. Expressions for the average currents in the devices for the leading and lagging legs in terms of load current $I_{o}=V_{d} D /(2 N R)$ and auxiliary current $I_{L a}=V_{d}(1-D) /\left(4 L_{a} F_{s}\right)$ are given in equation set (11).

For $D>D_{\text {boundary }}$ :

$$
\begin{aligned}
& I_{D 1+2}=\frac{(1-D)\left(T_{s} / 2\right)\left(I_{o} / 2 N\right)}{T_{S} / 2}=\frac{I_{o}}{2 N}(1-D) \\
& I_{D 3+4}=0 \\
& I_{S 1+2}=\left(\frac{I_{o}}{2 N}+I_{L a}\right) D \\
& I_{S 3+4}=\left(\frac{I_{o}}{2 N}-I_{L a}\right) D+\frac{I_{o}}{2 N}(1-D)=\frac{I_{o}}{2 N}-D I_{L a} .
\end{aligned}
$$

For $D<D_{\text {boundary }}$ :

$$
I_{D 1+2}=\frac{1}{2}\left(I_{L a}+\frac{I_{o}}{2 N}\right) \frac{(1-D) T_{s} / 2-t}{T_{S} / 2}=\left(I_{L a}+\frac{I_{o}}{2 N}\right)\left(\frac{(1-D)}{2}-\frac{t_{x}}{T_{s}}\right)
$$




$$
\begin{aligned}
I_{D 3+4} & =\left(I_{L a}-\frac{I_{o}}{2 N}\right) D+\frac{1}{2}\left(I_{L a}-\frac{I_{o}}{2 N}\right) \frac{t_{x}}{T_{s} / 2} \\
& =\left(I_{L a}-\frac{I_{o}}{2 N}\right) D+\frac{t_{x}}{T_{s}}\left(I_{L a}-\frac{I_{o}}{2 N}\right) \\
I_{S 1+2} & =\left(I_{L a}+\frac{I_{o}}{2 N}\right) D+\frac{1}{2}\left(I_{L a}-\frac{I_{o}}{2 N}\right) \frac{t_{x}}{T_{s} / 2} \\
& =\left(I_{L a}+\frac{I_{o}}{2 N}\right) D+\frac{t_{x}}{T_{s}}\left(I_{L a}-\frac{I_{o}}{2 N}\right)
\end{aligned}
$$

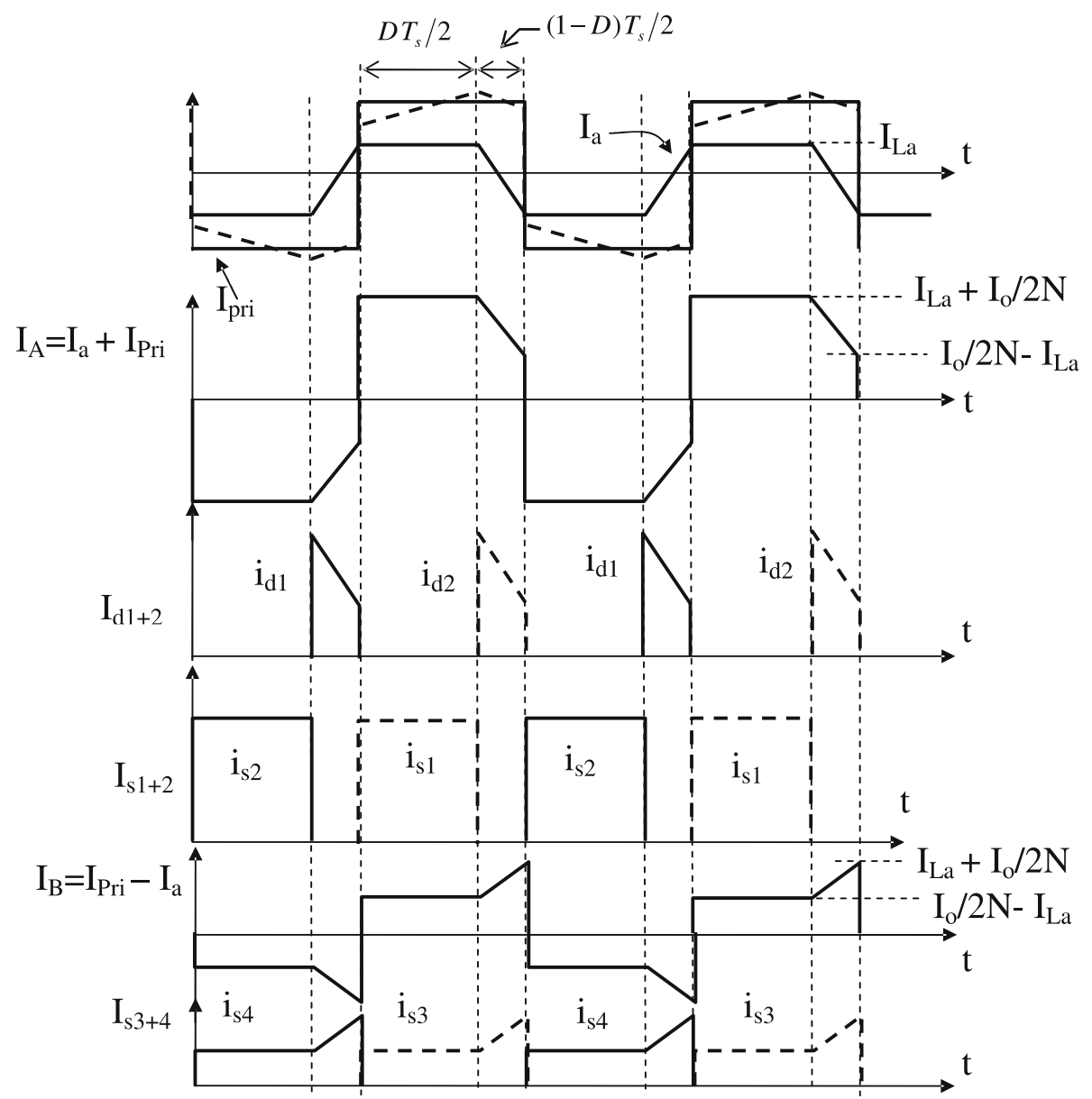

(a)

Figure 6a. (Continued) 


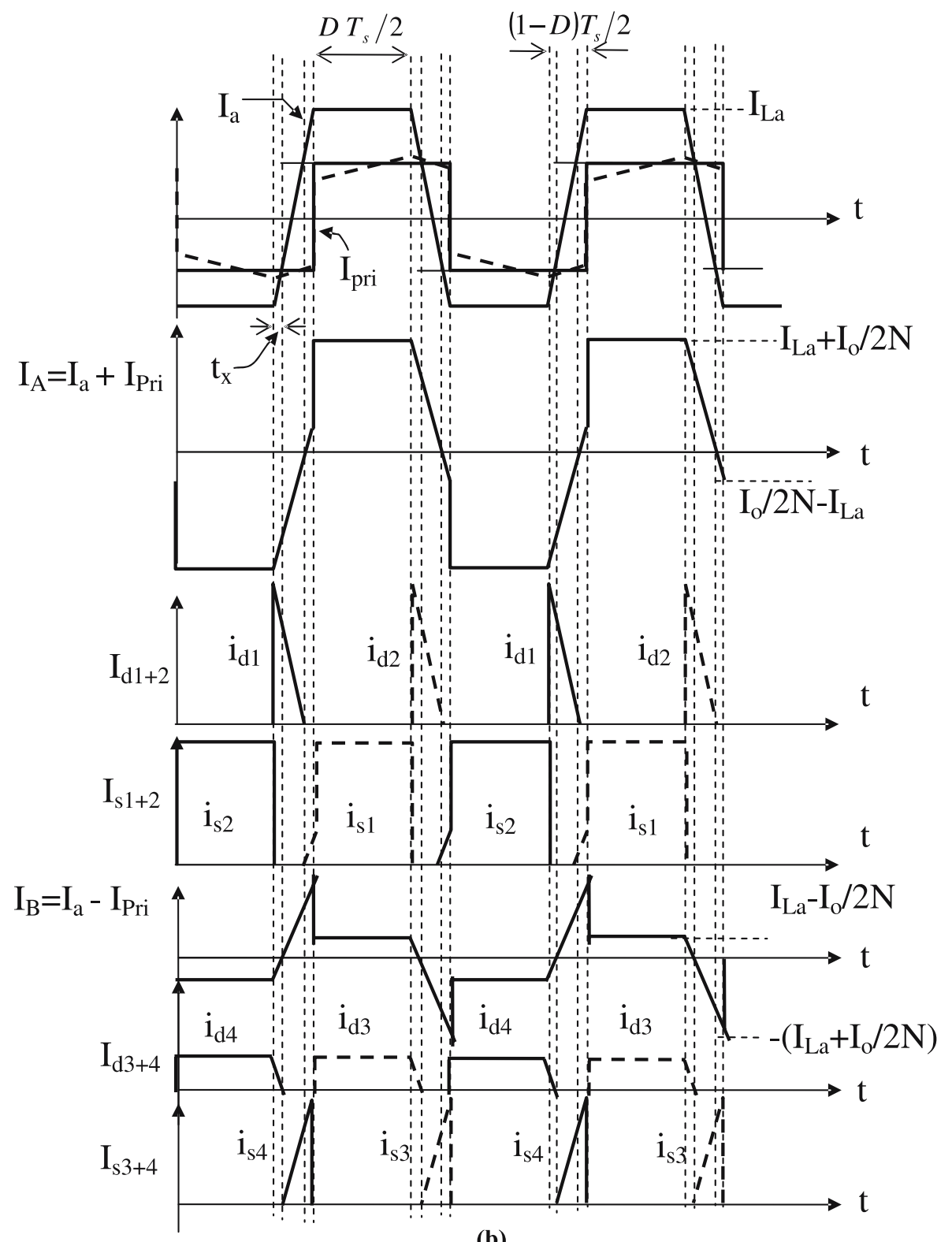

(b)

Figure 6b. Device current waveforms in new FBZVS converter for (a) $D>D_{\text {boundary }}$, and (b) $D<D_{\text {boundary }}$.

$$
\begin{aligned}
I_{S 3+4} & =\frac{1}{2}\left(I_{L a}+\frac{I_{o}}{2 N}\right)\left((1-D)-\frac{2 t_{x}}{T_{s}}\right) \\
& =\left(I_{L a}+\frac{I_{o}}{2 N}\right)\left(\frac{(1-D)}{2}-\frac{t_{x}}{T_{s}}\right) .
\end{aligned}
$$


Table 4. Expressions of conduction loss, core loss and winding loss in new converter with auxiliary circuit with adaptive current.

\begin{tabular}{ll}
\hline$P_{\text {conduction }}$ & $\frac{V_{d}}{8 F_{s} L_{a}}\left(V_{o n}+V_{d i}\right)-D^{2} \frac{V_{d}}{4 N^{2} R}\left(V_{d i}-V_{o n}-\left(V_{d i}+V_{o n}\right) \frac{L_{a} F_{s}}{2 N^{2} R}\right)$ \\
$\quad$ for $D \leq \frac{N^{2} R}{N^{2} R+F_{s} L_{a}}$ & $-D^{2} \frac{V_{d}}{8 F_{s} L_{a}}\left(V_{o n}+V_{d i}\right)$ \\
$P_{\text {conduction }}$ & $\frac{V_{d}}{4 N^{2} R}\left[D\left(V_{\text {on }}+V_{d i}\right)+D^{2}\left(V_{o n}-V_{d i}\right)\right]$ \\
$\quad$ for $D>\frac{N^{2} R}{N^{2} R+F_{s} L_{a}}$ & $P_{\text {core } e_{-} \max _{-} L a}(1-D)^{\alpha}$ \\
$P_{\text {core_La }}$ & $\left(\frac{V_{d}^{2}(1-D)^{2}}{48 L_{a}^{2} F_{s}^{2}}(2 D+1)\right) R_{\text {core }} L a$ \\
$P_{\text {winding_La }}$ &
\end{tabular}

The time interval $t_{x}$ (see figure $6 \mathrm{~b}$ for definition) is derived as,

$$
\begin{aligned}
& t_{x}=\frac{1}{4 F_{s}}-D\left(\frac{1}{4 F_{s}}+\frac{L_{a}}{4 N^{2} R}\right) \\
& D_{\text {boundary }}=\frac{N^{2} R}{N^{2} R+F_{s} L_{a}} .
\end{aligned}
$$

Next, the expressions for the conduction losses in each leg are derived. These losses along with core and winding loss in $L_{a}$ are listed in table 4.

\section{Comparison}

Figures 7-10 show the plots of device conduction losses, core losses, winding losses and total conduction losses, respectively, with changing duty cycle, for all four configurations. The only source of conduction loss in conventional FBZVS converter, i.e. device conduction loss has been included in figure 7 , in order to lay a reference level of device conduction loss. This level represents the minimum possible conduction loss in any FBZVS converter, as conventional FBZVS converter does not incorporate any additional auxiliary current. The parameters, chosen for the plots, are listed in table 5. In order to justify the comparison, choice of these parameters is such that respective peak primary currents and peak auxiliary currents are same in all configurations. For example, since the voltage across the $L_{a}$ in the new FBZVS converter is $\pm V_{d}$, the $L_{a}$ chosen is double as compared to other configurations, so that peak auxiliary currents in all configurations are same.

\subsection{Higher duty cycle operation}

At higher duty ratio operation, the converter with pole circuit at lagging leg shows increased conduction losses due to core and winding losses in auxiliary inductor [plot (1) in figures 8 and 9]. Converter with pole at both the legs also shows the same trend, with losses further increased, due to presence of two inductors [plot (2) in figures 8 and 9]. In the converter with passive auxiliary circuit, the additional device conduction loss and winding loss in the auxiliary inductor are minimal [plot (3) in figures 7 and 9], but the core losses in the auxiliary transformer make the total losses higher than the conventional FBZVS converter [plot (3) in 


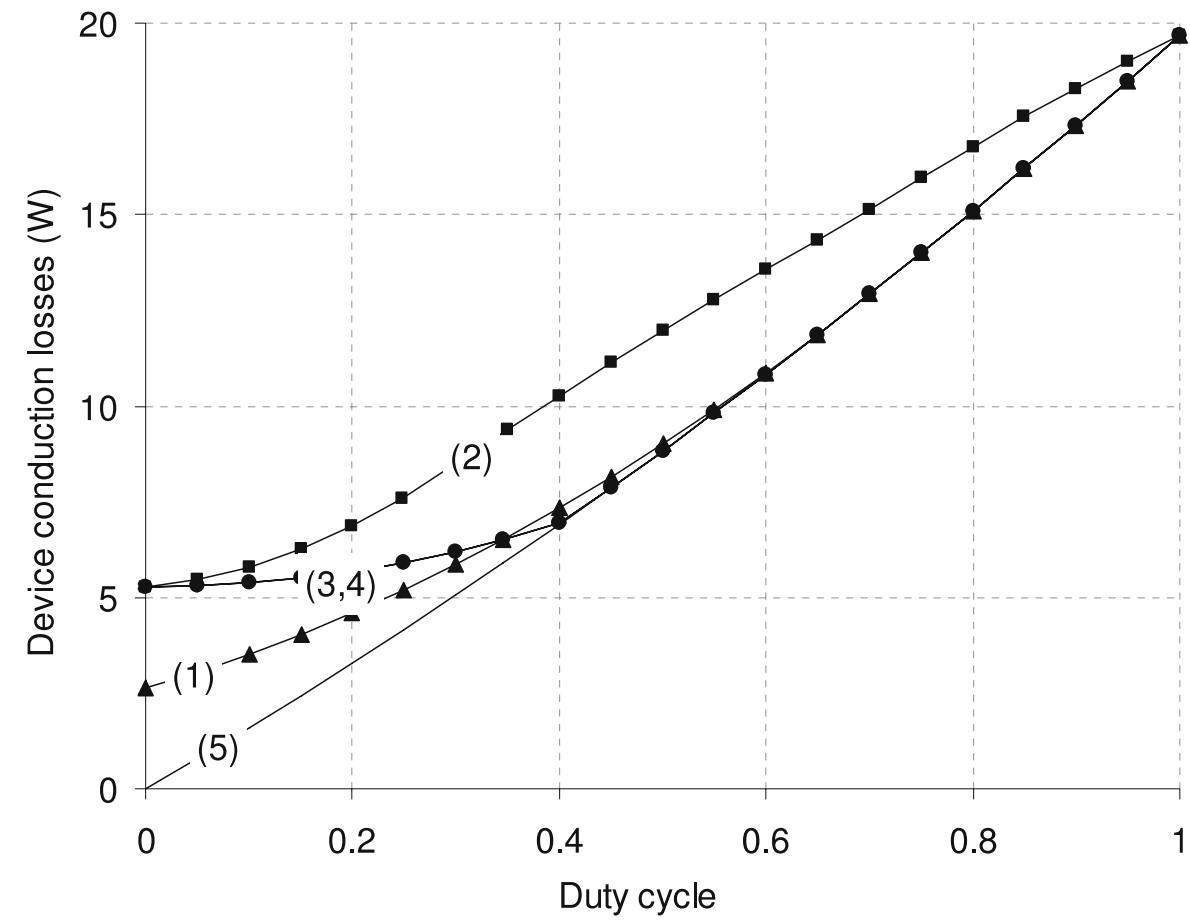

Figure 7. Device conduction losses in FBZVS converters. (1) Converter with pole at lagging leg $\left(L_{a}=120 \mu \mathrm{H}\right),(2)$ Converter with poles at both legs $\left(L_{a}=120 \mu \mathrm{H}\right)$, (3) Converter with passive auxiliary circuit $\left(L_{a}=120 \mu \mathrm{H}\right)$, (4) New FBZVS converter $\left(L_{a}=240 \mu \mathrm{H}\right)$, (5) Conventional converter.

figure 8]. In the new FBZVS converter configuration, the additional losses are minimal in all three forms [plot (4) in figures 7-9] and the loss curve converges to that of conventional FBZVS converter [plots (4) and (5) in figure 10], for higher duty cycle operation. Thus new FBZVS converter exhibits minimum conduction loss penalty with full-range ZVS operation.

Table 5. Design parameters for plots in figure 7. \#: for new FBZVS converter; *: for other converters.

\begin{tabular}{lccc}
\hline Parameter & Value & Parameter & Value \\
\hline$V_{d}$ & $250 \mathrm{~V}$ & $P_{\text {core, } \max }^{\#}$ & $2 \mathrm{~W}$ \\
$V_{o}$ & $0-10 \mathrm{~V}$ & $P_{\text {core } \max }^{*}$ & $1 \mathrm{~W}$ \\
$I_{o}$ & $0-50 \mathrm{~A}$ & $P_{\text {core } \max , T r}$ & $2 \mathrm{~W}$ \\
$F_{s}$ & $100 \mathrm{kHz}$ & $\alpha$ & $2 \cdot 5$ \\
$N$ & 9 & $R_{\text {coil }}^{\#}$ & $100 \mathrm{~m} \Omega$ \\
$R$ & $0 \cdot 2 \Omega$ & $R_{\text {coil }}^{*}=R_{\text {coil }, T r}$ & $50 \mathrm{~m} \Omega$ \\
$L_{a}^{\#}$ & $240 \mu \mathrm{H}$ & $V_{o n}$ & $2 \cdot 5 \mathrm{~V}$ \\
$L_{a}^{*}$ & $120 \mu \mathrm{H}$ & $V_{d i}$ & $1.5 \mathrm{~V}$ \\
\hline
\end{tabular}




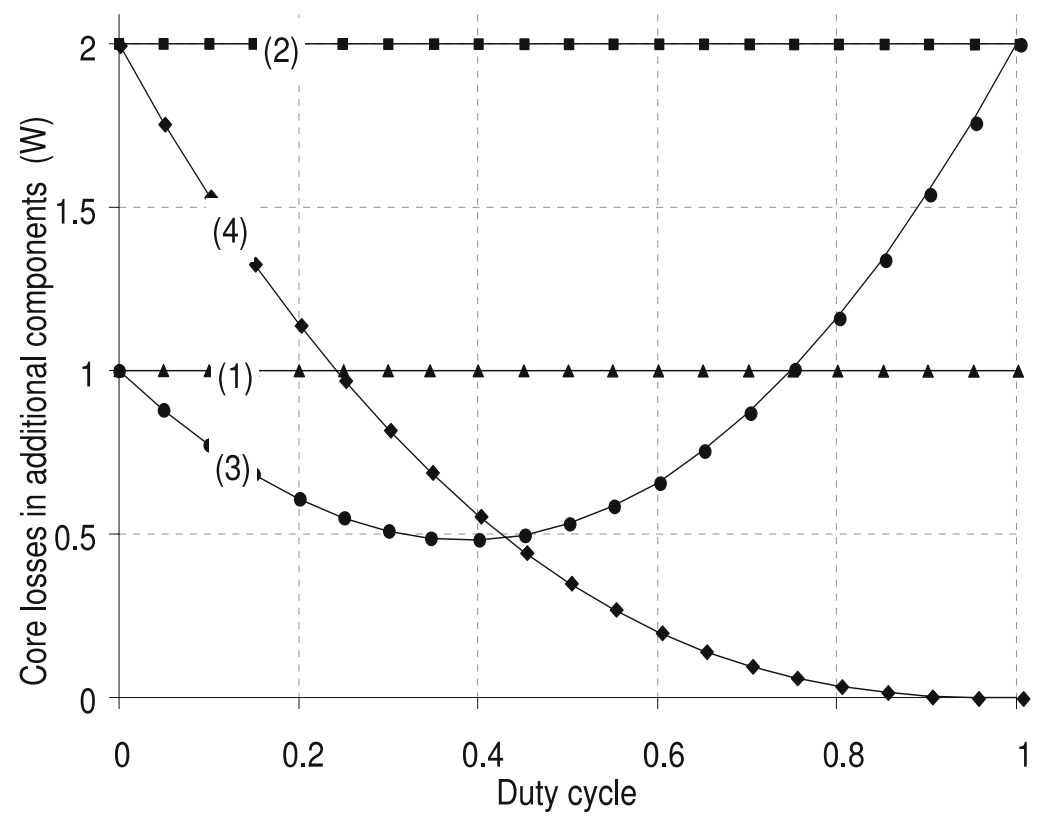

Figure 8. Core losses in FBZVS converters. (1) Converter with pole at lagging leg $\left(L_{a}=120 \mu \mathrm{H}\right)$, (2) Converter with poles at both legs $\left(L_{a}=120 \mu \mathrm{H}\right)$, (3) Converter with passive auxiliary circuit $\left(L_{a}=120 \mu \mathrm{H}\right),(4)$ New FBZVS converter $\left(L_{a}=240 \mu \mathrm{H}\right)$.

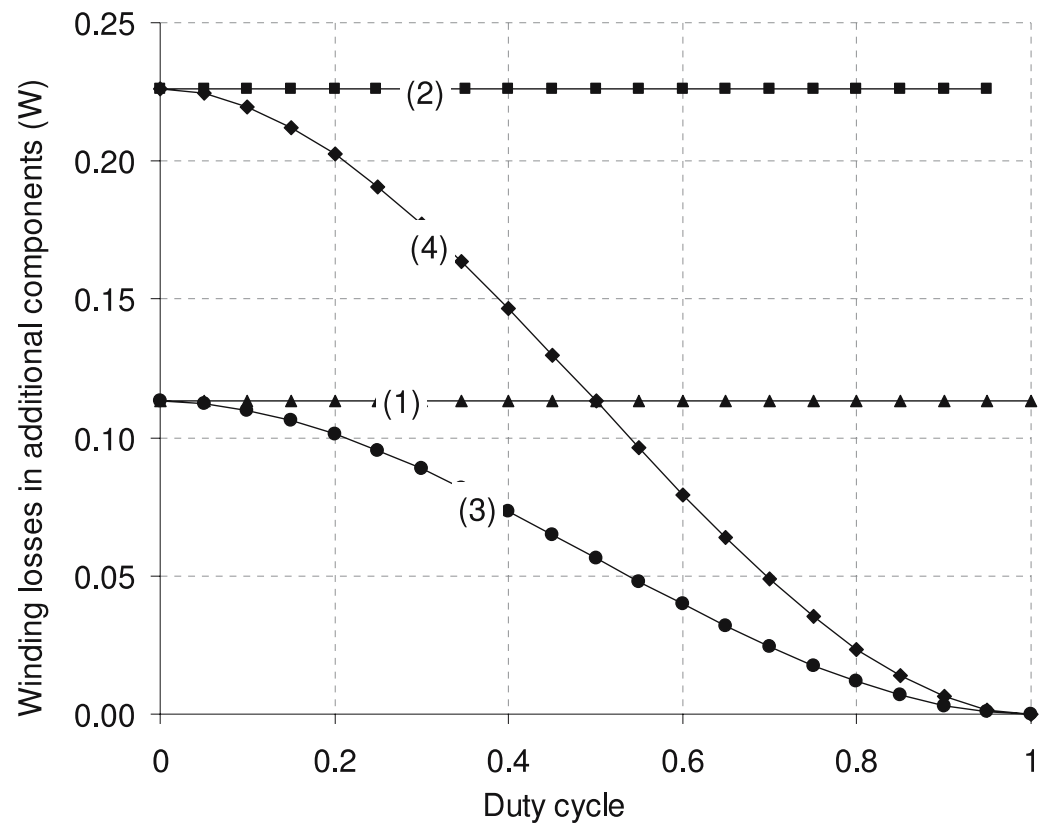

Figure 9. Winding losses in FBZVS converters. (1) Converter with pole at lagging leg $\left(L_{a}=120 \mu \mathrm{H}\right)$, (2) Converter with poles at both legs $\left(L_{a}=120 \mu \mathrm{H}\right)$, (3) Converter with passive auxiliary circuit $\left(L_{a}=120 \mu \mathrm{H}\right),(4)$ New FBZVS converter $\left(L_{a}=240 \mu \mathrm{H}\right)$. 


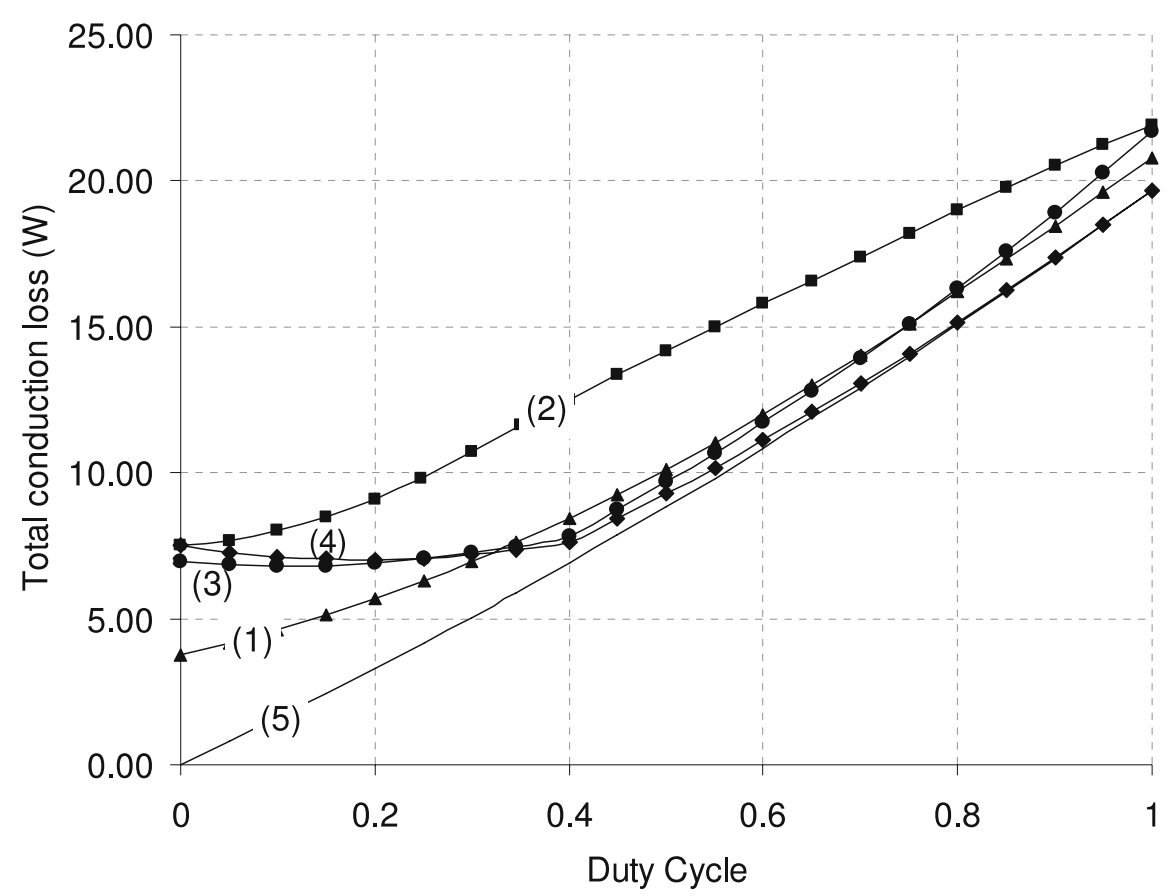

Figure 10. Total conduction losses in FBZVS converters. (1) Converter with pole at lagging leg $\left(L_{a}=120 \mu \mathrm{H}\right)$, (2) Converter with poles at both legs $\left(L_{a}=120 \mu \mathrm{H}\right)$, (3) Converter with passive auxiliary circuit $\left(L_{a}=120 \mu \mathrm{H}\right)$, (4) New FBZVS converter $\left(L_{a}=240 \mu \mathrm{H}\right)$, (5) Conventional converter.

\subsection{Lower duty cycle operation}

At lower duty cycle, the converter with lagging leg pole has low conduction losses [plot (1) in figure 7], but again this converter does not operate in ZVS mode for leading leg when $I_{p r i}$ reduces below critical level, causing switching losses. FBZVS converter with passive auxiliary circuit and new FBZVS converter have the similar loss profile [plots $(3,4)$ in figure 7] and the losses in the FBZVS converter with poles at both legs has the highest losses in this region [plot (2) in figures 7-10].

\section{Practical confirmation-Efficiency tests}

Conversion efficiencies of converters are measured on an experimental $500 \mathrm{~W}$ prototype converter operating at $100 \mathrm{kHz}$. The converter operates from a $250 \mathrm{~V} \mathrm{dc}$ input and delivers $50 \mathrm{~A}$ maximum in a load resistance of $0.2 \Omega$. The output current variation is specified in the range of $2 \mathrm{~A}$ to $50 \mathrm{~A}$. The switches $S_{1}-S_{4}$ are IRF840 MOSFETs. In the transformer, $N=9$. The output filter is: $L_{f 1}=L_{f 2}=22 \mu \mathrm{H}$ and $C_{f}=10 \mu \mathrm{F}$ [figure $1 \mathrm{f}, \mathrm{g}$ ]. The value of inductor is $L_{a}=120 \mu \mathrm{H}$ for the converters in figure $1 \mathrm{a}-\mathrm{d}$ and $L_{a}=240 \mu \mathrm{H}$ for figure 1e with $C_{d c 1}=C_{d c 2}=1 \mu \mathrm{F}$ [figure 1e]. The values of $L_{a}$ have been chosen such that peak auxiliary current remains equal in all configurations.

Figure 11 shows the efficiency test results for the converters. The efficiency of FBZVS converter with pole on lagging leg is shown as plot (2). From full-load to approximately $20 \%$ part-load, efficiency of the new FBZVS converter [plot (3)] is observed to be higher. 


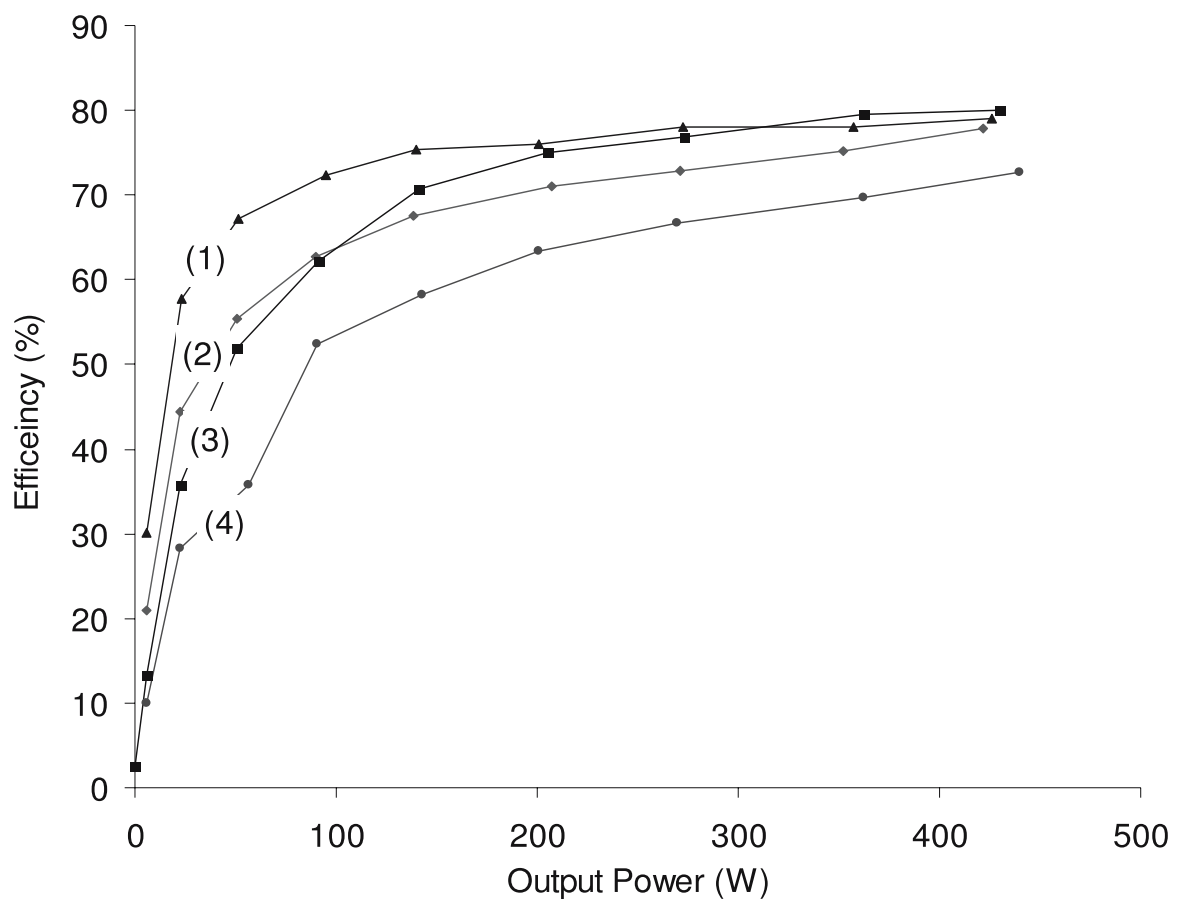

Figure 11. Efficiency of the $500 \mathrm{~W}$ prototype FBZVS converters. (1) Conventional converter, (2) Converter with pole at lagging leg, (3) New converter, (4) Converter with pole at both legs.

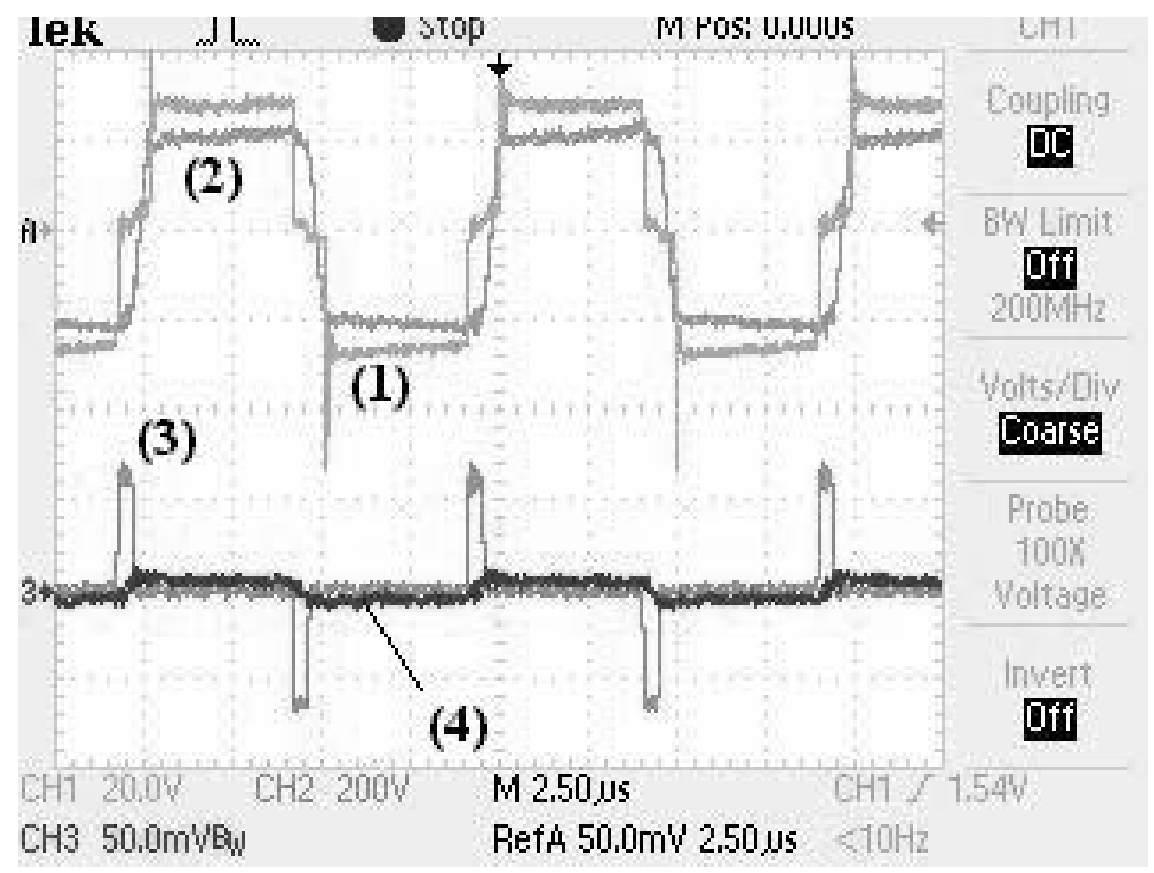

(a)

Figure 12a. (Continued) 


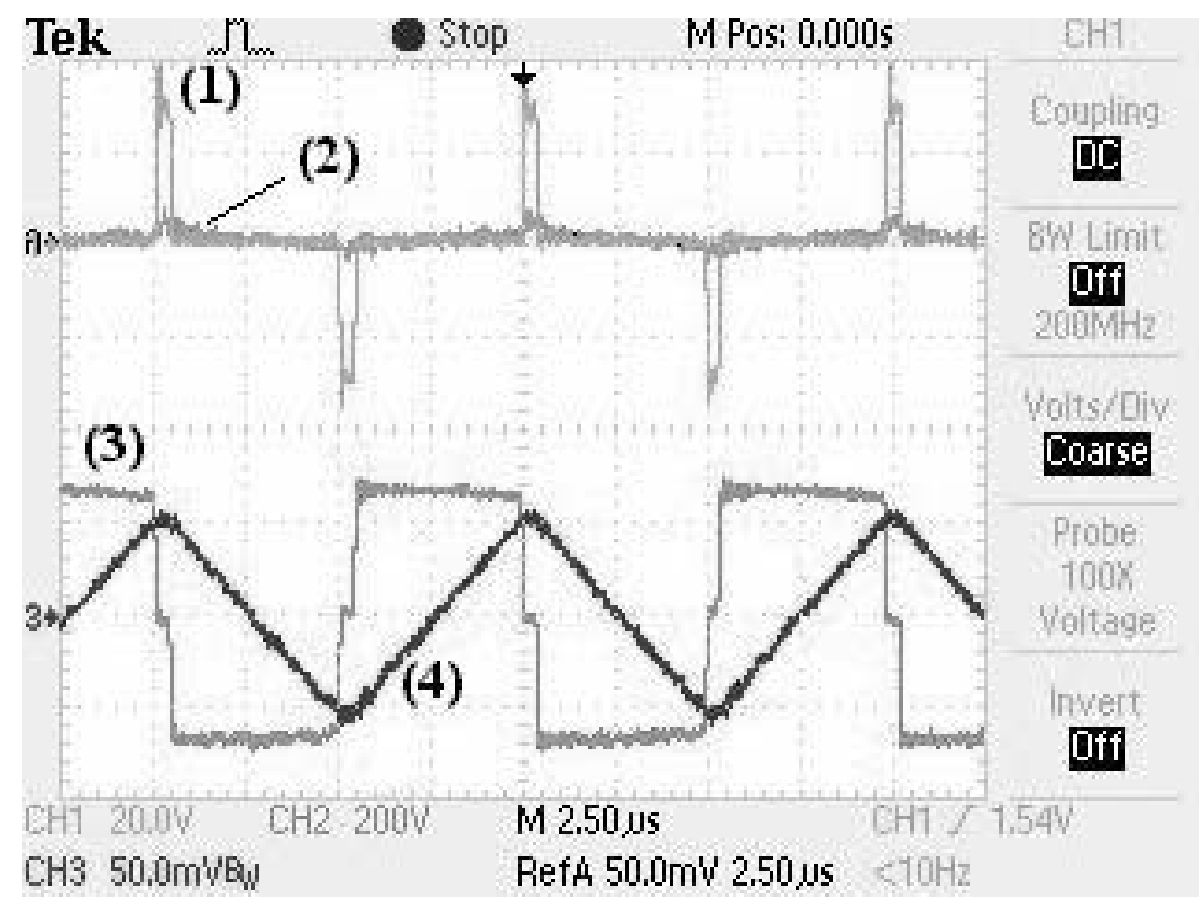

(b)

Figure 12b. Experimental Waveforms for the new FBZVS converter at (a) $D=0 \cdot 9$, and (b) $D=0 \cdot 1$. (1) Input voltage for the current doubler rectifier (20 V/div), (2) $I_{P r i}(2.5 \mathrm{~A} / \mathrm{div})$, (3) $V_{L a}(200 \mathrm{~V} / \mathrm{div})$ and, (4) $I_{a}(2.5 \mathrm{~A} / \mathrm{div}) . \mathrm{X}$-scale: $2 \cdot 5 \mu \mathrm{s} / \mathrm{div}$.

This is because the auxiliary current in the new FBZVS converter is lower than that in the FBZVS converter with pole on lagging leg. For lower output power, the efficiency of the new FBZVS converter is observed to be lesser. The reason is- in the FBZVS converter with pole on lagging leg, the auxiliary current is circulating in only two switches, providing ZVS in only lagging leg, whereas in the new FBZVS converter auxiliary current is circulating in all the four switches causing more conduction loss.

The efficiency of this FBZVS converter with poles on the both legs is shown as the plot (4) in figure 11. The efficiency is observed to be further degraded at full-load and also over the entire range as compared to the efficiency of the new FBZVS converter.

In summary, we can conclude that the fixed circulating current of FBZVS with pole on lagging leg and FBZVS converter with pole on both the legs degrades their full-load efficiency as compared to conventional FBZVS converter. Due to adaptive circulating current in new FBZVS converter, circulating current is low near full-load operation. Therefore, the fullload efficiency of the new FBZVS converter is the same as conventional FBZVS converter. The improvement in efficiency with the described full-range-ZVS techniques with respect to the conventional FBZVS converter at part-load operation depends on the trade-off between switching losses saved by maintaining ZVS operation and the additional conduction loss in the switches due to circulating current plus losses in the auxiliary inductor. The savings in the switching losses will be larger if either switching frequency is high (typically $300-500 \mathrm{kHz}$ in low-power applications, e.g. up to $1-2 \mathrm{~kW}$, using MOSFET) or the snubber capacitors are 
larger (tens of nano-farads) in high-power converters (e.g. up to 5-20 kW, using IGBT). With the chosen parameters of the prototype converter, the saving in the switching loss seems to be less than additional conduction losses. Therefore, for part-load operation, the efficiency of conventional FBZVS converter is observed to be higher. Nevertheless, the full-range ZVS operation of new FBZVS converter with minimum additional loss penalty remains as a major advantage since apart from efficiency improvement, there are other important reasons as explained in the introduction of this paper for ensuring full-range ZVS operation.

Illustratively, figure 12 shows the experimental waveforms of secondary voltage, primary current, voltage across $L_{a}$ and $I_{a}$ for the new FBZVS converter [figure 1e], (Borage et al 2008). The waveforms clearly demonstrate the adaptive auxiliary inductor current, which is high when the load current is low and vice versa resulting in full-range ZVS without increasing the full-load conduction losses.

\section{Conclusion}

Simplified analysis of losses in the full-bridge, full-range-ZVS circuits is presented and comparative assessment is made. Closed form expressions are derived for average value of device currents and losses. The loss curves for various topologies are plotted and compared. The analytical results are found to be consistent with the experimental efficiency tests performed on $500 \mathrm{~W}, 100 \mathrm{kHz}$ prototype. It is concluded that a recently proposed new topology has the least penalty of additional losses. The improvement in efficiency is expected in high frequency, high power operation wherein the switching losses saved exceed the additional losses incurred.

\section{Nomenclature}

$\begin{array}{ll}C_{d c 1}, C_{d c 2} & \text { DC blocking capacitors } \\ C_{f} & \text { Output filter capacitance } \\ D & \text { Duty cycle with respect to primary of transformer } \\ D_{b o u n d a r y} & \text { Value of } D \text { at which } I_{L a} \text { and } I_{p r i} \text { are equal } \\ F_{s}\left(=1 / T_{s}\right) & \text { Switching frequency } \\ I_{A} & \text { Current flowing away from left leg at its midpoint } \\ I_{a} & \text { Current flowing through the auxiliary inductance (auxiliary current) } \\ I_{B} & \text { Current flowing away from right leg at its midpoint } \\ I_{D 1+2} & \text { Total average current in diodes } D_{1} \text { and } D_{2} \\ i_{d 1}-i_{d 4} & \text { Current through diodes } D_{1}-D_{4} \text {, respectively } \\ I_{D 3+4} & \text { Total average current in diodes } D_{3} \text { and } D_{4} \\ I_{L a} & \text { Peak value of } I_{a} \\ I_{o} & \text { Output dc current } \\ I_{p r i} & \text { Primary current of the isolation transformer } \\ I_{s 1+2} & \text { Total average current in switches } S_{1} \text { and } S_{2} \\ I_{s 1+4} & \text { Total average current in switches } S_{3} \text { and } S_{4} \\ i_{s 1}-i_{s 4} & \text { Current through switches } S_{1}-S_{4} \text {, respectively } \\ L_{a} & \text { Auxiliary inductance } \\ L_{f 1}, L_{f 2} & \text { Output filter inductances } \\ L_{s} & \text { Leakage inductance of the isolation transformer (measured at the primary) } \\ N & \text { Transformer turns ratio (primary to secondary) } \\ P_{c o n d u c t i o n} & \text { Total conduction losses in the switches and diodes } \\ P_{c o r e} L a & \text { Core loss of inductor } L_{a}\end{array}$




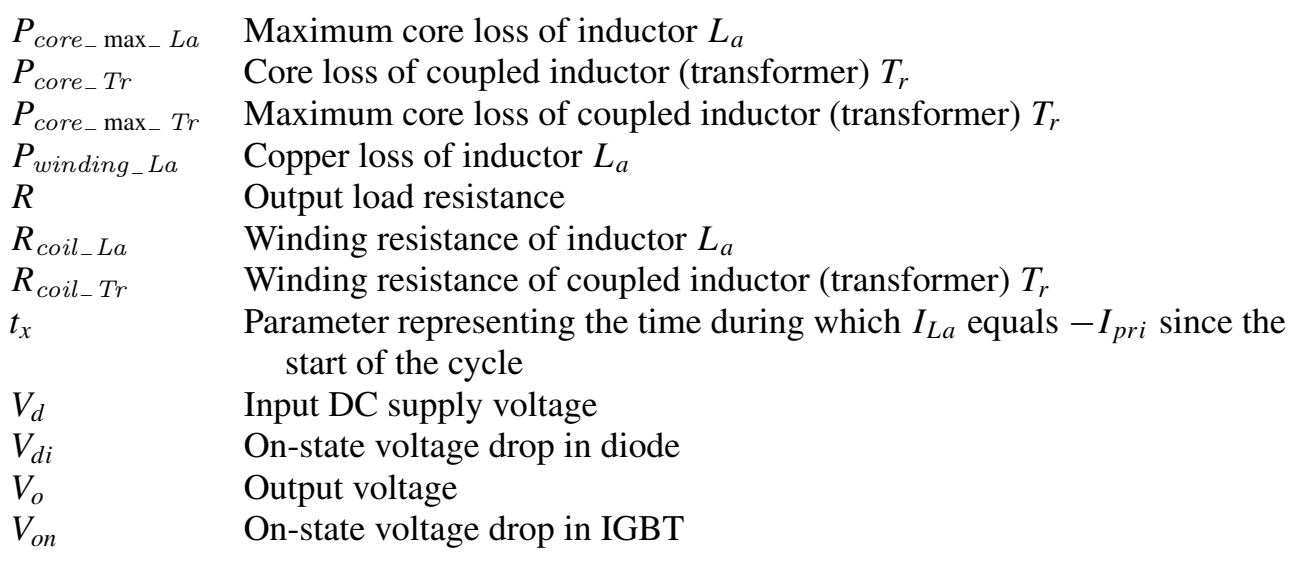

\section{References}

Borage M, Tiwari S, Bhardwaj S, Kotaiah S 2008 A Full-bridge DC-DC converter with zero voltage switching over the entire conversion range. IEEE Trans. Power Electron. 23(4): 1743-1750

Borage M, Tiwari S, Kotaiah S 2005 A passive auxiliary circuit achieves zero-voltage-switching in full-bridge converter over entire conversion range. IEEE Power Electron. Lett. 3(4): 141-143

Hua G, Lee F C, Jovanovic M M 1993 An improved full-bridge zero-voltage-switched PWM converter using a saturable inductor. IEEE Trans. Power Electron. 18(4): 530-534

Jain P K, Kang W, Soin H, Xi Y 2002 Analysis and design considerations of a load and line independent zero voltage switching full bridge DC/DC converter topology. IEEE Trans. Power Electron. 17(5): 649-657

Jang Yungtak, Jovnovic M M, Chang Yu-Ming 2003 A new ZVS-PWM full bridge converter. IEEE Trans. Power Electron. 18(5): 1122-1129

Sabate J A, Vlatkovic V, Ridley R B, Lee F C, Cho B H 1990 Design considerations for high-voltage high-power full-bridge zero-voltage-switching PWM converter. Proc. IEEE Appl. Power Electron. Conf. (APEC) 275-284

Watson R, Lee F C 1994 Analysis, design, and experimental results of a 1 KW ZVS-FB-PWM converter employing mag-amp secondary side control. Proc. IEEE Appl. Power Electron. Conf. (APEC) $166-172$ 